University of Rhode Island

DigitalCommons@URI

Open Access Dissertations

1978

\title{
Facilitation of Fear Reduction Following Electrical Stimulation of the Brain in Rats
}

William A. Pacitti

University of Rhode Island

Follow this and additional works at: https://digitalcommons.uri.edu/oa_diss

\section{Recommended Citation}

Pacitti, William A., "Facilitation of Fear Reduction Following Electrical Stimulation of the Brain in Rats" (1978). Open Access Dissertations. Paper 927.

https://digitalcommons.uri.edu/oa_diss/927

This Dissertation is brought to you for free and open access by DigitalCommons@URI. It has been accepted for inclusion in Open Access Dissertations by an authorized administrator of DigitalCommons@URI. For more information, please contact digitalcommons-group@uri.edu. 
FACILITATION OF FEAR REDUCTION FOLLONING

ELECTRICAL STIMULATION OF THE BRAIN IN

RATS

BY

WILLIAM A. PACITTI

A DISSERTATION SUBMITED IN PARTIAL FULFILLMENT OF THE REQUIREMENTS FOR THE DEGREE OF DOCTOR OF PHILOSOPHY IN

PSYCHOLOGY

UNIVERSITY OF RHODE ISLAND

1978 


\section{ABSTRACT}

This study assessed the efficacy of positive electrical stimulation of the brain in counterconditioning fear in 100 albino laboratory rats. A parametric investigation was undertaken in which fear was conditioned through presentation of electric foot shock and then reduced through response prevention, in combination with different types of electrical stimulation of the brain. The basic measure of fear was the Conditioned Enotional Response (CER), as seen in the suppression of licking behavior.

Electrical stimulation of the brain (ESB) has been used to effectively reduce active avoidance responding, another measure of conditioned fear, and its effects resemble closely those obtained when traditional reinforcers are used as counterconditioners. The CER procedure had not been used, however, to measure the reduction of fear following counterconditioning with rewarding electrical stimulation of the brain.

The effects of rewarding brain stimulation followed standard conditioning parameters and effectively reduced the fear complex more than non-rewarding brain stimulation or response prevention alone. ESB was then used to reassess a classical conditioning explanation of the reduction of conditioned fear following response prevention. 
TABLE OF CONTENTS

Chapter

Page

I. Introduction ............ 1

II. Method .............21

III. Results .......... 29

IV. Discussion ............. 59

APPENDICES

Appendix A. Design of the Study: $3 \times 3$

Analysis of Variance Showing

Al1 Treatment Groups .... 70

Appendix B. Histological Results ... . 71

REFERENCES ................ . . . . 73 


\section{LIST OF FIGURES}

Figure

1. Mean response suppression for number of 1icks on trials 1-5 combined . . . . . 33

2. Mean response suppression for number of licks on trial 1 alone . . . . . . 37

3. Mean response suppression for number of licks on trials 1 and $2 \ldots 41$

4. Mean response suppression for number of licks on trials 1,2 , and $3 \ldots 47$

5. Mean response suppression for time to 100 licks on trials 1 and $2 \ldots 50$

6. Mean response suppression for time to 100 licks on trial $1 \ldots 54$ 


\section{LIST OF TABLES}

Table

Page

1. Mean number of Licks and Standard

Deviations for Each Group on the last

Day of Training . . . . . . . . 30

2. Mean Response Suppression and Stand-

ard Deviations for Each Group for

Number of Licks on Trials 1-5 . . . . . . 32

3. ANOVA Surnmary Table for Response

Suppression on Number of Licks on

Trials $1-5 . . . . . . . . . .35$

4. Multiple Comparisons of Means Using the

Scheffé Method on Response Suppression

of Number of Licks for Trials 1-5 . . . . . 36

5. Dunnett's Test Comparing the A Priori

Control Group with all Means for Response

Suppression of Number of Licks on

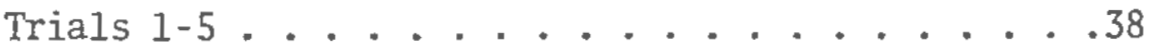

6. ANOVA Summary Table for Response Sup-

pression of Number of Licks on Trial 1 . . . . 39

7. Multiple Comparison of Means Using the

Scheffé Method on Mean Response Suppres-

sion of Number of Lic's for Trial 1 . . . . . 40 
8. Dunnett's Test Comparing the A Priori

Control Group with All Means for Response

Suppression of Number of Licks on Trial $1 . . . . .942$

9. ANOVA Sumary Table for Response Suppres-

sion of Number of Licks on Trials 1 and $2 . . . . .43$

10. Multiple Comparisons of Means Using the

Scheffé Method on Response Suppression

of Mean Number of Licks for Trials

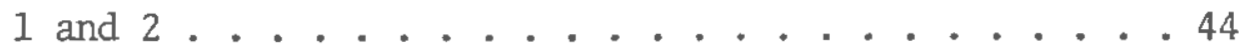

11. Dumnett's Test Comparing the A Priori

Contro1 Group with Al1 Means for Re-

sponse Suppression of Number of Licks

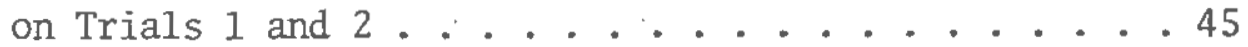

12. ANOVA Sumnary Table for Response Sup-

pression of Number of Licks on Trials

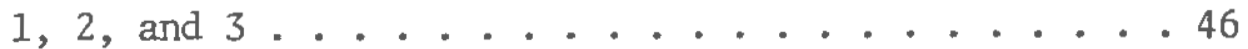

13. Multiple Comparisons of Means Using the

Scheffé Method on Response Suppression of

Number of Licks for Trials 1, 2, and 3...... . 48

14. Dunnett's Test Comparing the A Priori

Control Group with Al1 Means for Response

Suppression of Number of Licks on Trials

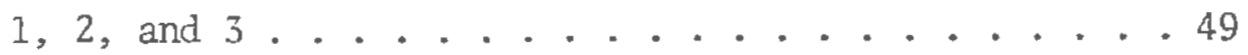


15. Mean Response Suppression and Standard Deviations for Each Group on Time to 100 Licks for Trials 1 and 2 . . . . . . . . 51

16. ANOVA Summary Table for Mean Response Suppression on Time to 100 Licks for

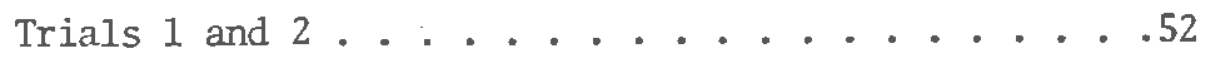

17. Multiple Comparisons of Means Using the Scheffé Method on Response Suppression for Time to 100 Licks for Trials 1 and

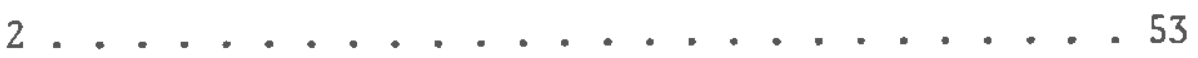

18. Dunnett's Test Comparing the A Priori

Control Group with All Means for Response Suppression for Time to 100 Licks for Trials 1 and 2 . . . . . . . . 55

19. ANOVA Summary Table for Mean Response Suppression on Time to 100 Licks for Trial ................ . 56

20. Multiple Comparisons of Means Using the Scheffé Method on Response Suppression of Time to 100 Licks on Trial 1 . . . . . . . 57

21. Dunnett's Test Comparing the A Priori Control Group with AIl Means for Response Suppression of time to 100 Licks . . . . . . 58 
It is well known in the area of conditioned fear that avoidance behavior in aninals can be made highly resistant to extinction (Solomon \& Wynne, 1953). It is also known that diffent methods exist for eliminating this avoidance behavior, some of which are more effective than others. One technique for reducing this avoidance responding, response prevention (RP), has proven to be one of the most effective and has been extensively used as the basic model in the animal analogue of the behavior therapy called implosive therapy. (Levis, 1966; Stampf1 ६ Levis, 1967; Baum 1969a).

In the typical avoidance conditioning experiment the animal is first forced to experience a stimulus (CS) in the presence of which it is subjected to noxious or aversive stimulation. The subject is then tested for the degree of learned fear to the CS. Once the fear is learned, the animal will usually actively avoid the CS by removing himself from the fearful situation for many trials. The effectiveness of this procedure in conditioning and measuring fear has been demonstrated many times since the work of Solomon \& Wynne (1953), and has been widely used since then in conditioning fear in laboratory animals.

After the conditioning of this avoidance behavior a further step of interest involves the treatments used to reduce it. Solomon, Kamin, \& Wynne (1953) were the first to develop an effective method of reducing this learned avoidance behavior. After using ordinary extinction procedures which proved unsuccessful, these experimenters introduced the RP treatment procedure, which consisted of physically preventing the avoidance response in the presence of the feared stimulus. 
Although numerous studies have demonstrated the effectiveness of the RP procedure in reducing the avoidance response beyond the results of simple extinction (Bankart \& Elliot, 1974; Baum, 1969a, 1969b, 1970; Berman \& Katzev, 1972; Schiff, et al., 1972; Shipley, et al., 1971 Solomon et al., 1953; Monti \& Sinith, 1976) the mechanisms underlying its effectiveness are still not clearly understood. Two-process fear mediation theory has most often been used as the theoretical framework for the explanation of the acquisition of the fear response (Mowrer, 1960), and the facilitative effects of RP in the reduction of fear are most often attributed to classical conditioning (Rescorla $\&$ Solomon, 1967).

Recent experiments have attempted to investigate means of further enhancing and understanding the efficacy of RP in hastening the extinction of avoidance behavior. Such things as social facilitation (Baum, 1969b), mechanical forced movement (Lederhandler \& Baum, 1970), and exposing the rat to a continuous loud buzzer (Baum \& Gordon, 1970) have been used to enhance extinction of the avoidance response and then used to infer that conditioned fear has been reduced.

Furthermore, it has been shown that an effective means of reducing fear and responding in an avoidance paradigm is to countercondition the fear with a positive reward (e.g. food). This approach (Nelson, 1966; Wilson \& Dinsmoor, 1970; Wilson ६ Davidson, 1971; Reid, 1973) involves pairing a previously conditioned aversive stimulus with positive reinforcement, thus making the incentive value of the original stimulus become positive (or at least no longer aversive). 
While the majority of the studies in the area of avoidance learning and extinction report a definite facilitation of extinction as a function of response prevention, the process by which response prevention produces the extinction is not altogether clear. Current theoretical analyses of fear reduction in the extinction of avoidance responding contain many controversies. Major questions involve whether it is actually fear that is being reduced in the RP procedure (Baum, 1969a,b). and if so what parameters of $\mathrm{RP}$ facilitate this reduction the most (Schiff, et al., 1972; Shipley, et al., 1971a; Shipley, et al., 1971b). Several experimenters (Page, 1955; Page \& Hall, 1953) have suggested that reduction of the avoidance response may actualiy be a result of leaming a new response to the still feared CS, rather than a reduction of the fear. Attempts at refuting this position have been made by using approach measures (Nelson, 1969; Page, 1955; Spring et al., 1974) but these studies have had problems of their own, since motivation to approach a previously feared CS must be introduced (Monti \& Smith, 1976). Monti \& Smith (1976) point out that what is needed for a clearer picture is a measure of fear unconfounded by responses present during fear acquisition, thus they employ the conditioned emotional response paradigm as their measure of fear.

The central question to which the present study was addressed involved whether or not the fear reduction that does take place follows the principles of classical two-factor theory (Mowrer, 1960). That is, does reduction of the avoidance-fear complex follow the principles of extinction, or as Rescorla and Solomon (196\%) suggest, is the extinction of conditioned fear a function of CS-UCS contiguity reduction. If the 
latter is truo, then changing the cont:gaity should result in fear reduction. This is what the countercouditioning approach atienpts. Nelson (1966) had demonstrated that aninals receiving food in the feared environment show more rapid extinction of the avoidance response than those who experience only the feared emironnent. Furthermore, if affectively positive stimuli are made contingent upon presentation of the feared CS when progranmed during response prevention, there is even more of a reduction of subsequent avoidance (Wilson \& Javidson, 1971; Reid, 1973). Gordon \& Baum (1971) made perhaps the clearest denonstration of the efficacy of counterconditioning by using positive electrical stimulation of the brain as the stinulus paired in the fear situation, and found that positive ESB greatly facilitated extinction of the avoidance response while non-rewarding $\mathrm{ESB}$ resulted in 10 great. er fear reduction than simple response prevention aione.

The use of FSB as a counterconditioner eliminates the problem of: inducing notivational states in subject: and hence controls prossible confounding variables. With the use of ESB it is now thought possible to precisely minipulace certain affective states of rats at the convenience of the experimenter. Nost of the work with ESB began in 1954 with the discoveries of Olds, Milner, and Delgado, who demonstrated that. direct stinuation of subcortical forebrain structures could be posit.ively reinforcing or aversive depending upon the exact site of stimulation, the jntensity, and the wave fcrm of the current used colds \& Milner, 1964; Olds, 1962, 1969).

The brain substrate that mediates the powerful effects of revarding 
ESB is the limbic brain system that evolved from a much more primitive olfactory forebrain. According to Olds (1976) and Milner (1976) this system appears to mediate reward and reinforcement independently of any particular drive or need such as hunger or thirst, and in a direct positive manner rather than in terms of a need reduction. The hypothalamus seems to be the critical link between brain stem regions that control many basic reflex mechanisms of motivated behavior and higher brain regions that mediate expressions of motivation (hunger, thirst, sex, etc.) This limbic forebrain system (particularly the Medial Forebrain Bundle) appears to have developed from an olfactory brain into a general system mediating pleasure and reward. Most theorists today (Olds, Milner, Delgado, Deutsch \& Gallistel; in Waquier \& Rolles 1976) describe the hypothalamus as the critical link between the biological machinery of motivated behavior and the subjective experience of needs and pleasure mediated by high brain regions.

Stimulation of the region of the medial forebrain bundle as it passes through the lateral hypothalamus seems to be an affect-eliciting stimulation which elicits central reward. Research in the area of ESB itself as reward suggests that the central reinforcement from this stimulation results in activating the ascending noradrenergic and dopaminergic neurons which are densely concentrated there (Thompson, 1975) Olds, Allan \& Briese (1971) carried out a detailed mapping of the kinds of behavior elicited by ESB along with central reward in the hypothalamus of the rat. With technical improvements (such as the microelectrode) they found that stimulation of the anterior region elicited 
only drinking, while stimulating the mid-lateral area elicited eating, only in the upper, dorsal portion. Self stimulatory behavior alone was elicited from the wider lateral region occupied by the medial forebrain bundle. An important finciing was that stimulation of the ventromedial nucleus produced satiety (tendency to inhibit or disrupt eating) but did not elicit self-stimulation. Stimulation of the mid-lateral area produced more mixed results. They (olds, et al., 1971) suggested that the hunger center in the lateral hypothalamus is separate and distinct from the self-stimulatory zone. Quite often artifactual results occur (ESB eliciting eating, gnawing, etc.) because the areas are close together anatomically, and stimulation with a large electrode would activate both regions. The general consensus at this time regarding the motivational substrates of ESB as central reward is that the self-stimulatory behavior is not part of any mechanistic system involved in feeding, drinking, or other activities. It is not drive reducing in the respect that it satisfies no known need, and it cannot be conceived easily as reducing a drive (Thompson, 1975). Stimulation of the ventro-medial area mimics satiation and stops eating (drive reducing but not reinforcing), while stimulation of the dorsal part of the lateral hypothalamus elicits hunger and causes eating (but is not reinforcing). Stimulation of the medial forebrain bundle is reinforcing but neither elicits nor reduces drives like hunger or thirst.

After 20 years of research in this area, we are now able to conclude that stimulation of specific subcortical sites will control behavior in a way that is analagous to conventional positive reinforcement Valenstein, 
1966, 1975; Deutsch \& Deutsch, 1966; Gordon \& Baum, 1971; 01ds, 1976; Milner, 1976). When positive ESB is programmed under the same experimental circumstances, the effects of the stimulation interact as one might anticipate using more conventional stimuli.

Subjective reports of human subjects receiving such stimulation of the brain are less clear (Delgado, 1972), and most people can't describe what is going on, yet overall they report it desirable. This result may be compared to other stimulation studies with humans using stimulation of other brain areas resulting in relatively specific reports, varying from forced motor seizures to pain relief in terminal cancer patients (Hosobuchi, Adarns, \& Linchitz, 1977).

Thus, positive ESB may be conceived of as comprising pure motivation or pure reward, and its effects mimic those of more conventional or "natural" reinforcers, even to the extent of serving to facilitate the reduction of a learned fear.

The basic finding regarding counterconditioning avoidance with positive ESB is that lateral hypothalamic ESB that supports rapid selfstimulation can, when delivered during RP, facilitate extinction of acquired fear (Gordon \& Baum, 1971; Hunsicker et al., 1973; Metja, et al., 1974).

Gordon \& Baum (1971) made the first attempt at using positive ESB in a counterconditioning situation. A $2 \times 2$ factorial design was used where two of the groups of rats received five minutes of RP while the other two spent an equal amount of time in a neutral environment (a plastic pail). RP consisted of thwarting the learned avoidance response while forcing the animal to remain in the feared situation. During the five minute period one RP group and one non-RP group received positive 
intracranial stimulation (coordinates of implantation site: 1.5 mm lateral; $2 \mathrm{~mm}$ anterior of the intra-aural 1ine; and $7.6 \mathrm{~mm}$ ventral from the surface of the cortex); the other groups were used to control for the effects of receiving the brain stimulation and one group received the same stimulation in a neutral situation, outside and away from the avoidance apparatus. The fourth group received neither RP nor ESB. The rewarding ESB (lateral hypothalamic stimulation) was chosen by these authors specifically because it could be manipulated independently of the animal's drive state or ongoing behavior. For acquisition, Gordon \& Baum (1971) compared median number of shocks received in acquisition and median number of trials to criterion, and found no significant differences between groups. During extinction, however, their results showed dramatically more rapid extinction of the avoidance for the RP plus ESB group, when median number of responses in extinction and median latency of the first response in extinction were used as measures of residual fear.

This finding was further supported by Hunsicker, Nelson, $\mathscr{G}$ Reid, (1973) who pointed out that the positive ESB was potentially a very complex stimulus, which might have eleicited many responses besides just positive affect. These other reactions in Gordon \& Baum's (1971) study might have included forced movement, and when not contingent upon a particular response, active locomotion and exploratory behavior. These other responses may, in fact, have been "distracting" enough to reduce avoidance responding in extinction and give the impression that it was instead, reduced fear. 
Hunsicker et al., (1973) point to the difficulty in drawing any unequivocal conclusions about counterconditioning processes when the above reactions were not controlled for, and even more so prior to the Gordon \& Baum (1971) study when only more conventional positive reinforcing stimuli had been used. Hunsicker et al., (1973), therefore, attempted an understanding of the essential counterconditioning properties of positive ESB by comparing the counterconditioning efficiency of positive ESB with the nonreinforcing ESB that elicited forced movenent, and from their data it was possible to segregate the effects of movement eliciting ESB from the positive affective qualities of ESB as a positive reinforcer.

Hunsicker et al., (1973) used a factorial design $(3 \times 3)$ in which they varied length of exposure to the feared stimulus along with the type of ESB presented. Three of the groups of rats received no exposure to the CS, three received 2.5 minutes of $R P$, and three received no ESB, three groups received positive ESB (aimed at the same coordinates as Gordon \& Baum, 1971), and three groups received ESB that elicited forced movement. The basic finding, which replicated that of Gordon \& Baum (1971) was that rats receiving positive ESB during the longer response prevention time (five minutes) responded the least when given the opportunity to avoid the feared stimuli in subsequent extinction trials. Rats receiving no ESB and no $R P$ were thought of as a no-treatment control group, and their performance was used as a standard for comparison. It was determined that only the treatment of positive ESB during 2.5 and 
5.0 minutes of response prevention met statistical standards indicating reliable differences. These three groups met the standard for the measures of trials and "avoidances" to criterion, but only the group with positive ESB during the five minutes of response prevention met the standard on time to the first response.

All their data (Hunsicker, et a1., 1973) overwhelmingly indicated that positive ESB during response prevention produced marked reduction in responding compared to other treatments. Other data have also been obtained which show that positive ESB efficiently attenuated persisting avoidance in a signalled lever pressing situation (Reid, 1973) .

Hence, across laboratories and experimenters, in different paradigns and in the same paradigm, lateral hypothalamic ESB has been shown to be effective in producing rapid extinction of active avoidance when. it is delivered during response prevention.

The studies of Gordon \& Baum (1971) and Hunsicker et al., (1973) have recently been scrutinized by Metja et al., (1974) and in the process partially replicated. Basically, the results of all three studies were the same: RP with periodic ESB efficiently deconditioned the avoidance, and RP by itself was no more effective than no treatment. Metja's et al., (1974) criticism of the Gordon \& Baum study (1971) and the Hunsicker et al., (1973) experiment lay in the possibility that the conclusions derived might have been limited because the distribution of subjects into experimental groups was potentially biased, since non self-stimulating rats were placed in control groups. Results of Metja's own series of studies (1974), however, strongly confirmed that whatever differences 
might have existed between groups in previous studies, due to possible differential site of electrode placement, they were not sufficient to influence the outcome of the studies. Metja's (1974) results, when controlling for these differences, supported Gordon \& Baum's (1971) original findings by quoting substantial data taken from other studies in their lab. Voss et a1., (1974) for example, trained rats 100 trials a day for 10 days and then provided the same three treatments used in the other experiments (no treatment, RP alone, and RP plus positive ESB). They found that five minutes of RP and ESB reduced persisting avoidance by about one half. With 30-minute treatments, however, RP and ESB completely eliminated avoidance, while 30 minutes of RP alone provided only a slight reduction in responding. This same result of RP and ESB being more effective than RP alone was demonstrated by Baum et a1., (1973); Buss \& Reid, (1973); and Paxton, et al., (1975) .

There are two reports in the literature of procedures using positive ESB that did not result in a reduction of avoidance behavior. In one of these studies (Prado-Alcala, et al., 1973) the training, treatment, and testing were the same as in the Metja et al., (1974) study, except that treatment times were only one or two minutes. Evidently treatments consisting of one or two minutes of RP with ESB are too short to be effective. The other study (LeClerc et al., 1973) showed little effect of adding ESB to RP, but it was done with stimulation sites more anterior to the electrode sites of other studies. It is unclear at this time whether the reduced effectiveness of anterior electrode placement was attributable to the reduced affective value of 
the sites, or to some special characteristics of the respective ESB'S (Metja et a1., 1974). The safest conclusion to be drawn from the above data is that lateral hypothalamic ESB that supports rapid selfstimulation when delivered during RP can reduce subsequent active avoidance responding to the CS. Response prevention that is brief (one or two minutes), in comparison to the extent of training, produces either a slight increase over no treatment, or no reliable mean differences compared to a no-treatment control group, and produces large variability in responding across rats.

A very important feature of nearly every test with brief RP is that for some rats responding is actually enhanced (Reid, 1973). These results are somewhat analogous to those of Coulter, Riccio, \& Page (1969) and Rohrbaugh, Riccio, \& Arthur (1972) who have shown that with relative1y short CS durations during RP there seens to be a paradoxical enhancement of fear to the CS. Prolonged RP (5-30 minutes) on the other hand, when paired with positive ESB, does effectively reduce avoidance responding compared to equal times of $\mathrm{RP}$ alone.

One large gap exists in the literature regarding ESB facilitated response prevention. To this date, the only measure of fear used has been the active avoidance where the rat first escapes from the feared stimulus then learns to avoid it by running down an alley or climbing up on a shelf (e.g. Baum \& Gordon, 1970). Up to the present, treatment using ESB has consisted of simply giving the aninal 5 to 30 minutes of RP with the CS on continually, and interspersing electrical stimulations to the brain during that time on some schedule (one every .5 second, etc.). 
While the data strongly support the fact that presenting these stimulations during $R P$ facilitates extinction of the avoidance response, no explanation of how the process occurs is possible using this paradigm. Reference is made to two-factor theory (Gordon \& Baum, 1971) and a general "relaxational" response during ESB, using classical conditioning explanations for the counterconditioning effect. No published study to date, however, has used appropriate pairing of CS (feared stimulus with the ESB (supposedly the new UCS) controls, or for that matter, no study even attempted to vary the pairing methods parametrically.

Thus, one major objective of this study was to fill in this gap in the literature by conducting an experiment directly aimed at answering the question of whether or not the RP fear reduction is due to classical counterconditioning. If it follows the classical laws of learning, then certain pairing methods should be effective in facilitating the fear reduction (e.g. delay conditioning should result in fear reduction), while other pairing methods (randomized pairing as suggested by Rescorla, 1967) should not result in fear reduction. If it is not the pairing method itself, but only the presence of the ESB or the presence of the CS alone, then the pairing methods should show no difference in the degree of fear reduction achieved when the methods are varied.

Along with lack of empirical support for the classical conditioning foundation, the fact that previous studies have used only the oneway avoidance and signalled avoidance paradigm to assess amount of fear has greatly limited generalization of theoretical explanations of the fear reduction method to other situations (e.g. implosive therapy). If 
ESB is truly effective in reducing the conditioned fear, then this reduction should be found when other indices of fear or enotionality are used.

One of the greatest difficulties besetting the behavior theorist is that when he applies the usual experimental procedures to the training of avoidance behavior, he discovers that they are much more effective with some avoidance responses than with others (Bolles, 197S). Probably the most rapid learning in the active avoidance situation occurs in the one way situations. Under this paradigm, Bolles concludes that after receiving about four shocks under almost any conditions, the rat will run from the shock compartment to the safe compartment. Once this behavior is established it is executed with approximately 100 per cent proficiency and requires about 100 trials to extinguish.

Matsch. (19S9) shocked rats in a box from which they could leap onto a surrounding ledge and found that this response was often established after a single shock trial. Part of this rapid learning may be attributed to the fact that this response is close to what Bolles might call a species specific defense reaction. During their evolution and up to the present, rats supposedly were continually preyed upon by larger carnivores. The primary defense of rats when threatened is freezing. Conversely, when rats are exposed to aversive stimulation of some duration, jumping and scrambling are the typical responses that follow freezing. These two general responses of rats to aversive stimulation (usually shock in the 1ab) freezing upon threat, and jumping to escape, interact to determine the form of avoidance response in any particular fear conditioning study (Bo11es, 1973). 
Rats are very poor at acquiring a lever pressing response to turn off signalled foot shock. They will learn to press to escape the shock, but do not readily press to avoid the shock. The signal for the shock first leads to freezing usually just in front of the lever or at the start box of the alley, and the onset of the shock goads them to jump at the lever (Reid, 1975), or begin running. Rats will readily learn to run from a place of shock and do not readily approach a place where shock was previously given. Consequently, rats learn, with a moderate amount of training, a one-way avoidance but have difficulty acquiring a two-way avoidance. An advantage of a two-way avoidance paradigm is that it can be run without the necessity of picking up the rat after every trial, thereby controlling for the potential confounding effects of handling, and also making it easier to automate the apparatus. One advance in programming of this type of avoidance was made by Baum (1965) who progranmed an automated one-way avoidance situation consisting of a shelf upon which the animal climbed to first escape and eventually avoid the CS. Still, in order to measure the fear in the active avoidance paradigm, it is necessary for the animal to learn to make some movement in space, whether it is down a runway or, as in Baum's (1965) apparatus, up on a shelf off the grid floor.

Alternatives to fear reduction have been suggested to explain the reduction in active avoidance responding after RP. Page (1955) suggested that RP serves to instrumentally condition a new response (e.g. freezing, crouching) which is reinforced by the absence of shock. This "competing response" theory maintains that 
the conditioned fear has not been extinguished. Page argues that a1though reduction in the Conditioned Avoidance Response (CAR) has been facilitated by RP, latencies to approach the avoidance chamber for food were significantly longer for blocked than non-blocked subjects. Page concludes that the animals who underwent blocking (RP) were in fact more frightened than anjmals extinguished in a normal fashion.

Other measures are available, however, and two in particular may be more sensitive than the one way avoidance. One of these is the conditioned emotional response (CER). The CER, as developed by Estes \& Skinner (1941), takes advantage of the rat's first and prepotent reaction to anything it finds fearful: freezing and doing nothing for a while. The measure has been used repeatedly in the literature and consists of simply establishing a steady rate of some ongoing operant (lever pressing, licking water from a tube, etc.) and then introducing the feared stimulus (usually an auditory CS). The rat, if subjected to shock in the presence of this noise on an earlier occasion, immediately stops what it is doing (eating, drinking, lever pressing, etc.) crouches and freezes. Taking a measure of pre-CS rate of behavior and a measure of during-CS behavior, one can calculate a suppression ratio, a number that represents how much the ongoing behavior of the animal has been interrupted. It is generally considered that the CER procedure has provided more complete and reliable information than any other method regarding the determinants of conditioned fear (Church, 1971).

Monti \& Smith (1976) have recently used a lever press CER to successfully measure fear reduction caused by standard response prevention 
treatment. They suggested that many earlier studies examining RP did not reveal residual fear because the techniques used were not sensitive enough. They also showed that aside from the ability of the white noise CS to elicit fear, environmental stimuli became conditioned stimuli capable of eliciting fear. Overa11, they assess the CER paradigm as being an extremely sensitive index of fear, particularly sensitive to the residual fear that may not be observed in the conditioned avoidance situation where extinction is used as the primary measure.

Possible criticisms of the CER technique have been cited in the literature (Corriveau and Smith, 1977). One limitation might be the introduction of inadvertant experimenter bias in the CER situation, for subjects who don't readily acquire the operant response are typically excluded from the experiment. Secondly, the technique is costly in terms of effort (training the subjects on the operant). A third consideration is that assessment of fear is performed in an environment other than where fear was conditioned. In view of the ability of cues (apparatus) as fear eliciting conditioned stimuli (CS) it would seem desirable to test fear reduction in the same apparatus where it was originally conditioned. Testa (1976) also suggests that the CER does not preclude the presence of competing response behavior prompted by the presence of the CS during testing. The CER has not, however, been employed in a direct counterconditioning situation, where positive ESB is explicitly paired with the CS and then residual fear tested.

An alternative to measuring fear in the one way avoidance situation has been the passive avoidance situation where after fear conditioning 
and RP treatment the subject is required to make some approach response in the "feared" environment (Page, 1955; Riccio \& Silvestre, 1973; Corriveau \& Smith, 1977). In this situation fear is assessed by recording latencies to approach a previously avoided CS situation. Recent evidence (Corriveau \& Smith, 1977) suggests that this measure may be just as sensitive as the CER, and unconfounded by competing responses (as in Page, 1955; Riccio \& Silvestre, 1973) and appears to be particularly sensitive to type of residual fear seen in Monti \& Smith's (1976) study.

The major hypothesis of this study was that RP and ESB work to facilitate fear reduction through classical counterconditioning. A second hypothesis was that the effects of ESB should respond to standard conditioning parameters. The major prediction that followed was that ESB presented during CS exposure would facilitate fear reduction more than just the CS alone ( $R P$ or flooding) treatment. This facilitation in fear reduction should be evident in the delay conditioning groups but not in the randomly paired group, where there was no contiguity specified. From the data on RP or flooding alone, it was predicted that presenting the CS alone would reduce fear to a certain degree, but not as much as when the CS was explicitly paired with the Positive ESB. The subjects who received the CS alone should experience fear reduction (through the process of classical conditioning extinction), and the amount of CS exposure (RP) should differentially effect the amount of fear reduction. Furthermore, subjects who received the forced movement ESB should not experience any more fear reduction than the CS alone subjects, for the forced movement ESB has no reinforcing qualities 
and hence should be ineffective as a counterconditioner.

An important feature of the present study was that the effectiveness of the ESB in facilitating fear reduction was measured in a new situation, specifically the CER using the lick response. Licking was chosen as the operant because it is perhaps the easiest operant to condition in rats, being a highly prepotent behavior, and eliminates many of the problems cited by Corriveau \& Smith (1977). After water deprivation, the lick may be conditioned reliably in all subjects within one 15-minute shaping session and produces a high, stable rate of behavior from that point on (Nageishi G Imada, 1964; Yoshida, et al. 1969). The CER using this response should provide a cleaner measure of the deconditioning of fear using ESB facilitated RP than the one-way avoidance situation of Baum (1965) and Baum $q$ Gordon (1970), and provide a very sensitive measure of residual fear to the CS (Monti \& Smith, 1976).

A second purpose was to replicate the basic finding of ESB facilitated fear reduction (Gordon \& Barm, 1971; Humsicker et a1., 1972; Metja et al., 1947) in the CER situation in a different laboratory.

Table 1 (see Appendix A) presents the $3 \times 3$ design, 1isting the main treatment (counterconditioning) variables. The experiment was run in several phases. During the surgical phase electrodes were chronically implanted, and then screening for ESB effects took place. The second phase was the lick training phase, during which all subjects were trained to lick from a tube for water reinforcement to a predetermined criterion. After lick training, all subjects were conditioned to fear a white noise CS by pairing the noise with a strong electric foot shock. After fear 
conditioning, all subjects underwent the various treatments specified by Table 1, and type of CS-ESB pairing method was varied along with number of CS-ESB pairings. After treatment each subject was returned to lick situation where the CER measure of response suppression was taken. The animal began licking for water, and then after a predetermined number of 1 icks was made, the white noise came on for a specified period of time. The number of licks that the aninal made during a preCS period was recorded, along with number of licks made during the CS, and a suppression ratio was calculated for that particular test period. Five test periods were given during the test session. In addition to the number of 1icks, the time it took each subject to make 100 licks in the pre- and during-CS periods was recorded. Pilot work indicated that this latency measure might have been more sensitive than the number of licks, for it took into account the initial suppression that the animal experiences with the onset of the CS, something that might have been lost when only the number measure was recorded. 


\section{NETHOD}

\section{Subjects}

The subjects were 100 male albino rats obtained from the Charles Rivers Breeding Laboratories, weighing 200-250 gm each at the time of electrode implantation. The aninals were housed two to a cage and maintained on ad lib feeding and drinking schedules until 72 hours before surgery. At this time all animals were separated, and after elect-

rode implantation remained in individual cáges. All subjects remained on ad lib food and water until ESB screening was completed. Forty eight hours before the first day of lick training each subject was water deprived while food remained in their cages.

\section{Apparatus}

All animals received chronic unilateral implants using a Kopf Model 1204 stereotaxic device. Following surgery each subject received self-stimulation training in a single lever box, $25.40 \mathrm{~cm} \mathrm{x}$ $22.86 \mathrm{~cm} \times 19.05 \mathrm{~cm}$, containing one standard Scientific Prototype rat lever. Upon depression of the lever, stimulation was automatically delivered from a square wave source (Grass !lodel S-48 Stimulator) at an intensity which was varied manually. One train of stimulation was delivered for each press, each lasting .5 sec. Stimulation was delivered through wound insulated bipolar electrodes, with a diameter of .005 in., conmercially available from Plastic Products Company (stock \#9515) . 
The lick training apparatus consisted of two isolated chambers, each fitted with a standard plexiglass box, $25.40 \mathrm{~cm} \times 22.86 \mathrm{~cm} \times$ $19.05 \mathrm{~cm}$, a 15 watt overhead light, and a silent exhaust fan. Mounted on the lid of each box was an eight inch 8 ohm round speaker. Mounted on the left wall of each box was a $5 \mathrm{~cm}$ long, $1 \mathrm{~mm}$ diameter hollow stainless steel tube, which was connected to a Lehigh Valley Electronics Co. \#114-06 Liquid Solenoid valve. Connected to the tube and the grid floor of each chamber was a lick sensitive AND Gate (Testan Co., "10602), which was activated when the rat placed its tongue on the tube. Each lick delivered approximately .1 ml of tap water.

The CER conditioning apparatus consisted of another plexiglass chamber with the same dimensions as the lick chambers, but with no manipulandum present. The CS was a $.5 \mathrm{sec}$ white noise "burst" delivered from a Grason Stadler \#901B noise generator. Shock was delivered by a BRS Foringer Model SG-901 shock generator through the grid floor of the box, and consisted of one .5 second, 2.0 ma pulse, immediately following presentation of the noise.

During lick training, treatment, and test phases of the experiment the primary dependent measure was number of licks made. These were recorded during every phase of the experiment on electro-mechanical counters, and totals printed out with a Coulbourn print out counter. Solid state timers recorded how long it took each animal to make 100 licks in each phase of the test period. These latencies were used as a second dependent measure. 
Procedure

Implantation and Self-stimulation training. Electrode sites were either the right lateral hypothalamus or the internal capsul-crus cerebri. Stimulation of the hypothalamus in the forebrain bundle produces positive reinforcement with a minimum amount of forced movement, whereas stimulation of the internal capsule activates efferent fibers evoking gross movements (Hunsicker et al., 1973) .

The stereotaxic coordinates were: $1.7 \mathrm{~nm}$ right of bregna, 2.0 mon posterior, and $8.1 \mathrm{~mm}$ ventral from the surface of the cortex (Konig \& KIippel, 1963) for Positive ESB. For Forced Movement ESB the coordinates were $3.5 \mathrm{~mm}$ right lateral, $2.0 \mathrm{~mm}$ posterior, and $7.0 \mathrm{~mm}$ ventral from the surface of the cortex.

Three days after the operation, the animals were screened for self-stimulation behavior or forced movement. The animals remained on a schedule of 15 minutes access to the stimulation per day until their bar pressing rates stabilized to within $20 \%$ variability on three consecutive days. Each ESB animal received five, 15 minute sessions of lever press training where the optinal current was individually determined for each animal to maximize bar pressing rates. This same current level was then used during the counterconditioning treatment phase of the experiment. This procedure is similar to that used by Gordon \& Baum (1971) and Hunsicker et al., (1973).

Forced movement was tested for in all subjects assigned to the non stimulating forced movement ESB groups. Only rats which did not 
self-stimulate when given a yoked number of shaping stimulations as a member of the positive ESB group, and which showed marked physical movement with each stimulation were included in the forced movement group. Each forced movement animal was yoked to a positive ESB aninal in number of stimulations both during shaping and training, so number of stimulations was held constant during this phase for the ESB and FM groups. Subjects that were included in the sham-operated (NO ESB) CSalone groups were prepared exactly like the Positive ESB subjects except they never received positive ESB paired with a CS as a counterconditioning treatment following their fear conditioning.

Lick Training. After ESB-lever press screening and training, all subjects were placed on a 48 hour water deprivation schedule while remaining on ad lib food. All subjects received five days of 1ick training consisting of 15 minutes per day access to crf water reinforcement. Twenty four hours after the last session of lick training, all were conditioned to fear a white noise stimulus (CS). The CS was presented on a variable 30 second schedule; .5 seconds of the CS was followed immediately by .5 seconds of 2.0 ma shock (US) delivered through the grid floor. Each subject received 20 such pairings of noise and shock.

Treatment. After fear conditioning all subjects underwent the treatment phase. Basically a $3 \times 3$ factorial design was employed (refer to Table 1, Appendix A) but ten groups in all were used, the extra group being a Positive ESB randomized control. Major treatment variables were the type of ESB-CS pairing method and the number of CS-ESB pairings. 
Types of ESB-CS pairing were (four levels): Positive ESB Delay pairing, Forced Movement ESB Delay pairing, No ESB-CS Pairing, and an a priori control using Randomized pairing. Number of pairings ( 3 levels) were: 0 CS-ESB Pairings, 50 CS-ESB Pairings, or 150 CS-ESB Pairings. The individual treatments were given as follows (again refer to Table 1, Appendix A):

1. 0-CS, Positive ESB (PESB-0). Subjects in this group received one .5 second stimulation to the lateral hypothalamus every 8 seconds (variable) for a total ESB exposure of 150 stimulations and 75 seconds.

2. 50-CS, Positive ESB Delay Conditioning (PESB-50). Subjects in this group received one .5 second stimulation following each of 50 CS presentations. Each CS presentation was 1.5 seconds, followed immediately by one .5 second presentation of ESB to the lateral hypothalamus. Total CS exposure was 75 seconds, and total ESB exposure was 25 seconds.

3. 150-CS, Positive ESB Delay Conditioning (PESB-150). Subjects in this group received one stimulation following each of 150 CS presentations. Each CS was .5 seconds, followed inmediately by a single .5 second burst of ESB to the lateral hypothalamus. Total CS time was 75 seconds, and total ESB time was 75 seconds.

4. 0-CS, Forced Movement ESB Delay Conditioning (FM-0). Subjects in this group were treated exactly like the PESB-0 group except they received stimulation to the internal capsule. Total ESB time was 75 seconds.

5. 50-CS, Forced Movement ESB Delay Conditioning (FM-50). Subjects 
in this group were treated exactly like the PESB-50 group except stimulation was given to the internal capsule. Total ESB exposure was 25 seconds, total CS exposure was 75 seconds.

6. 150-CS, Forced Movement ESB Delay Conditioning (FM-150). Subjects in this group were treated exactly like PESB-150 subjects except stimulation was given to the internal capsule. Total FSB was 75 seconds; and total CS time was 75 seconds.

7. 0-CS, No FSB (CS-0). Subjects in this group spent an equal amount of time in their home cage next to the apparatus as the other treatment groups spent in their counterconditioning chamber, (approximately 25 minutes), but received neither ESB nor CS exposure.

8. 50-CS, No ESB (CS-50). Subjects received 50 presentations of the $1.5 \mathrm{sec} C S$, but no stimulation. Total CS time was 75 seconds.

9. 150-CS, No ESB (CS-150). Subjects received 150 presentations of the . $5 \mathrm{sec} C S$, but no stimulation (as the CS-50 group). Total CS time was 75 seconds.

10. 150-CS, Positive ESB Randomized Control (PESB-R). Subjects in this a priori control group received one stimulation to the lateral hypothalamus on the same schedule as the PESB-150 group, except the CS presentations were programmed randomly throughout the session. Total number of CS exposures was 150 (total time of CS was 75 sec.). Total number of ESB exposures was 150 (total time was $75 \mathrm{sec}$.).

Test Phase. Immediately after the end of the treatment, each subject was returned to the lick apparatus and the water was again made available of a crf schedule. Al1 subjects were a1lowed to make 251 icks before the first test period began to establis! an equivalent baseline. 
On the 26th lick the first test period began. The number of licks made in the first one minute interval following the 25th lick was used as a measure of pre-CS rate. After this one minute interval the white noise CS came on for one minute and the number of licks was again recorded. On a variable one minute schedule following the first during-CS interval the next test trial was begun. Five test trials in all were given, with the dependent measures being the number of licks made and the latency to the 100th 1ick.

Once all pre and during-CS rates and latencies were recorded, they were converted to the basic measure of response suppression specified by Church (1968), the suppression ratio. This number is an index of how much ongoing behavior has been suppressed, and was derived from the formula $B / A+B$, where $A=$ the number of responses made during the pre-CS interval and $B=$ the number of responses made during the CS. The particular ratio used in this study was $A-B / A$, which ranged from a negative number (indicating facilitation) to 0 (no suppression, no facilitation) to +1 (complete suppression). For the latency measure another suppression ratio was calculated: $B-A / B$, where $A=$ latency to the first 100 licks in the pre-CS interval and $B=1$ atency to 100 licks in the duringCS interval. Latency ratios again ranged from a negative number (facilitation) to 0 (no suppression) to +1 (complete suppression). If a subject failed to reach the criterion of 100 licks in the one minute pre and during periods, it was assigned the number 601 (in hundreths of a second) and the ratio calculated from that. 
When an animal completed the test phase of the experiment it was perfused with a solution of $10 \%$ formalin and its brain removed from the skull. The brain was then left in a formalin solution for at least 10 days. Following this procedure, histology was then performed on a randomly selected sample of subjects. Twenty subjects in all were selected for histology, where the brain was sectioned on a microtome and the frozen sections mounted on slides and stained. Two subjects were randomly selected from each of the experimental groups for histological verification of electrode placement. Fourteen subjects with electrodes aimed at the lateral hypothalamus were examined, while six subjects with electrodes aimed at the internal capsule received histological examination. 
RESULTS

Three days after each animal was operated on it was screened for self-stimulation or forced movenent. All subjects met the criteria for PESB and FM, in fact 63 out of the 70 rats with implants aimed at the lateral hypothalamus were shaped to press the lever well within the first 15 minute session. The remaining seven subjects were all shaped by the third session. In all Positive ESB groups there was a minimm of forced movement, and by the fifth day of training all subjects had stabilized their bar pressing rates to within $20 \%$ variability.

of the $30 \mathrm{FM}$ subjects who had electrodes aimed at the internal capsule, 25 emitted gross forced movement with each stimulation (rolling over on their side, etc.). The remaining five subjects emitted a lesser degree of forced movenent yet it was still readily apparent (consisting mostly of head turning to the side). None of the FM animals could be shaped to press the lever when a yoked number of shaping stimulations were provided. Each FM aninal received the same number of shaping stimulations as its yoked PESB animal.

After self stimulation screening all subjects were then water deprived and received training in the lick chamber. No significant differences occurred between treatment groups when mean number of licks on the last day of training were compared with the Analysis of Variance (F ratio less than one). 
Table 1 below presents means and standard deviations for each group on number of Licks on Day 5 of Lick Training.

\section{TABLE 1}

Mean Number of Licks and Standard Deviations for each Group on the Last Day of Training

GROUPS

\begin{tabular}{lrrrrrr} 
& PESB-0 & PESB-50 & PESB-150 & \multicolumn{1}{l}{ FM-0 } & FM-50 & FM-150 \\
M & 1324.83 & 1193.31 & 1146.90 & 1394.22 & 1198.81 & 1431.66 \\
SD & 421.05 & 258.72 & 471.32 & 230.58 & 477.60 & 380.94 \\
& & & & & & \\
& CS-0 & CS-50 & CS-150 & PESB-R & & \\
SD & 1272.10 & 1280.39 & 1316.55 & 1108.40 & & \\
\hline
\end{tabular}

Twenty-four hours after the last lick training session fear conditioning and the counterconditioning treatments occurred. Immediately after the last fear conditioning trial each animal experienced a counterconditioning-RP session. After the last treatment pairing each animal ias returned to the lick apparatus where the test phase of the experiment began. Following the last test period each animal's number of licks in the test phase was converted to the suppression ratio specified above, along with his latency to 100 licks in each of the test periors. 
Overall, the results supported the major hypotheses and predictions. Fear reduction was facilitated when delay classical conditioning procedures were employed for pairing rewarding brain stimulation with the previously feared CS. Table 2 contains means and standard deviations for the primary measure of response suppression, number of licks made in the five test periods. 
Table 2

Mean Response Suppression and Standard

Deviations for Each Group for Number of Licks, Trials 1-5

TRIALS

\begin{tabular}{|c|c|c|c|c|c|}
\hline Group & & $I$ & $I-2$ & $1-3$ & $1-5$ \\
\hline \multirow[t]{2}{*}{ PESB-O } & $\underline{M}$ & .9214 & .7197 & .6381 & .5343 \\
\hline & $\underline{S D}$ & .1552 & .2547 & .3535 & .3739 \\
\hline \multirow[t]{2}{*}{ PESB- 50} & $\underline{\mathrm{M}}$ & .3573 & .3729 & .2623 & .2379 \\
\hline & $\underline{\mathrm{SD}}$ & .4446 & .2975 & .2379 & .2954 \\
\hline \multirow[t]{2}{*}{ PESB-150 } & $M$ & .0356 & .0105 & .0199 & -.1452 \\
\hline & $\underline{\mathrm{SD}}$ & .2700 & .3778 & .4337 & .2679 \\
\hline \multirow[t]{2}{*}{ FM-O } & $\underline{M}$ & .8629 & .7334 & .7641 & .6763 \\
\hline & $\underline{\mathrm{SD}}$ & .2026 & .2802 & .2663 & .2917 \\
\hline \multirow[t]{2}{*}{$F M-50$} & $\underline{\mathrm{M}}$ & .5601 & .4032 & .3219 & .3226 \\
\hline & $\underline{S D}$ & .1742 & .3278 & .2857 & .3296 \\
\hline \multirow[t]{2}{*}{ FM-150 } & $\underline{M}$ & .4227 & .4630 & .4496 & .4319 \\
\hline & $\underline{S D}$ & .3462 & .3230 & .4467 & .2487 \\
\hline \multirow[t]{2}{*}{$\mathrm{CS}-\mathrm{O}$} & $\underline{M}$ & .7056 & .7178 & .6809 & .5847 \\
\hline & $\underline{S D}$ & .3591 & .2268 & .1677 & .2120 \\
\hline \multirow[t]{2}{*}{ CS- 50} & $\underline{M}$ & .4626 & .4494 & .3323 & .3963 \\
\hline & $\underline{S D}$ & .4660 & .3600 & .3025 & .2490 \\
\hline \multirow[t]{2}{*}{ CS-150 } & $\underline{M}$ & .5367 & .4527 & .5187 & .5638 \\
\hline & $\underline{\mathrm{SD}}$ & .3752 & .4634 & .4261 & .3383 \\
\hline \multirow[t]{2}{*}{ PESB-R } & M & .5322 & .4515 & .3798 & .3506 \\
\hline & $\underline{S D}$ & .3015 & .3654 & .4645 & .2591 \\
\hline
\end{tabular}


Figure 1. Mean response suppression for number of licks on trials 1-5 combined. 


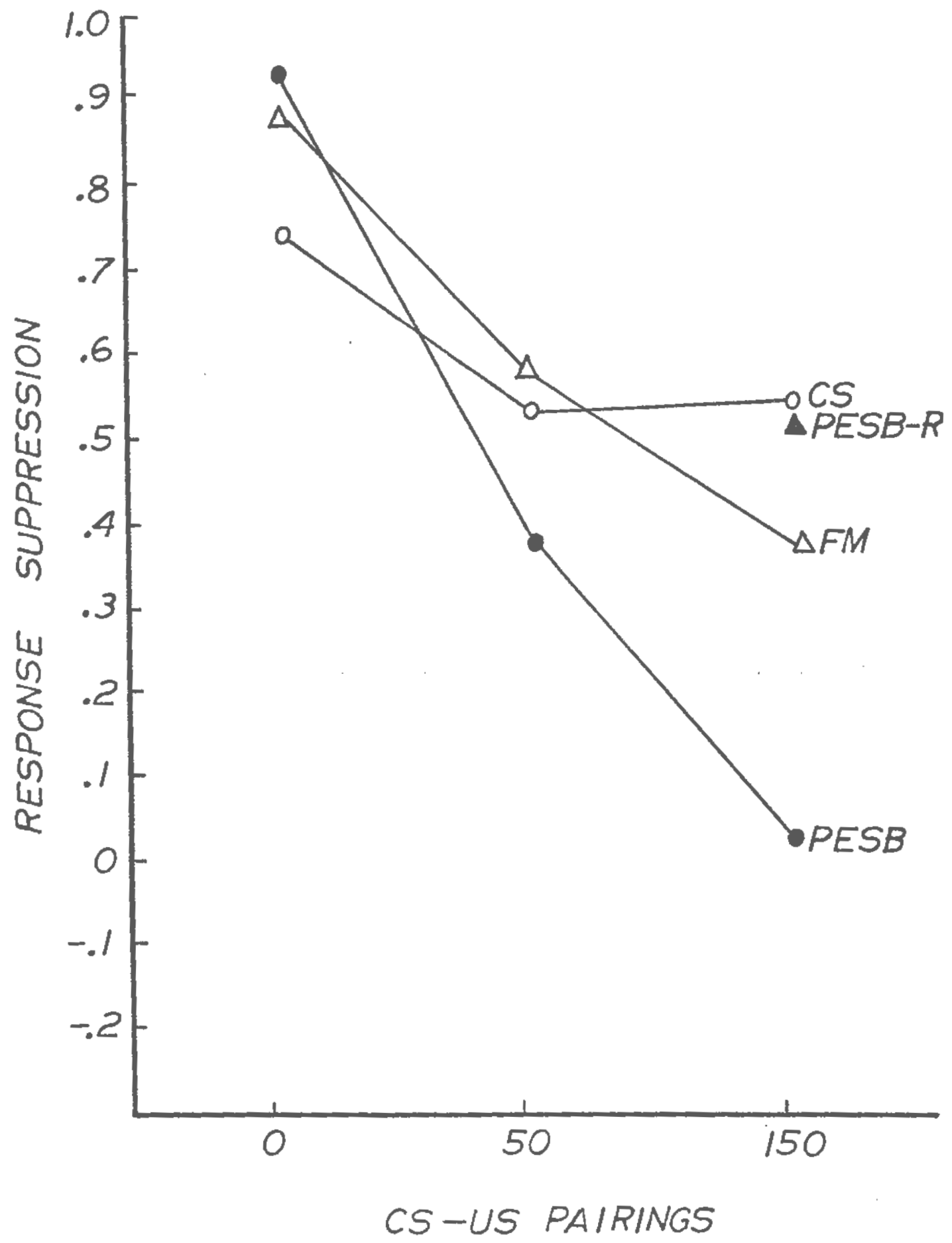


As seen in this table, and in Figure 1, mean response suppression was attenuated as would be predicted from standard classical conditioning parameters: As number of delay pairings with positive ESB increased, amount of respons suppression was reduced. This reduction was much less apparent when non-rewarding brain stimulation (Forced Movement stimulation) was used, or when the CS was employed alone. Also, little reduction in suppression occurred when ESB and CS were presented in a randomized fashion.

After the measures (number of licks and latencies) were converted to the suppression ratios seen in Table 2, variances were calculated. The FMAX test was performed according to winer (1965), and the variances proved not significantly different. The two factor analysis of variance was then performed on the $3 \times 3$ design. All subsequent anaiyses of variance employed the within groups variation ( $\left.M S_{W}\right)$ as its error term.

Figure 1 shows the nean response suppression for number of licks for trials 1-5 combined. As seen in the figure, the most significant reduction in response suppression occurred in the Positive ESB conditions. This was supported by the results of the ANOVA and subsequent multiple comparison tests. The results of the ANOVA (see Table 3) indicated a significant treatment effect for type of stimulation: $\underline{F}(2,81)=39.49$, p.001; and for number of pairings: $E(2,81)=30.50, p<.001$. A significant ESB $\times$ Pairings interaction also occurred with $F(4,81)=$ 53.74, p .001. 
Table 3

ANOVA Sumnary Table for Response

Suppression of Number of Licks on Trials 1-5

\begin{tabular}{lrrrr}
\hline Source & SS & df & $\underline{M S}$ & $\underline{F}$ \\
\hline Tota1 & 11.2102 & 89 & & \\
ESB & 2.0301 & 2 & 1.0151 & $39.49^{*}$ \\
Pairings & 1.5604 & 2 & .7814 & $30.50^{*}$ \\
ESB $x$ & 5.5200 & 4 & 1.3813 & $53.74^{*}$ \\
Pairings & & 81 & .0257 & \\
Error & 2.0811 & & & \\
\hline${ }^{*}<.001$ & & &
\end{tabular}

As the type of electrical stimulation of the brain was varied from one that was positively reinforcing to one that was neutral (forced movement) there was a significant change in the amount of response suppression observed. Also, the more pairings of ESB and CS in a delay conditioning situation, the more effective the ESB was in reducing the response suppression. The significant interaction resulted from the fact that ESB seemed to work more when the number of pairings was 150 , as compared to when the same stimulation was given, but oniy paired 50 times with the previously feared CS, resulting in a total ESB exposure of 25 seconds. 
Following the ANOVA, multiple comparison tests were performed to determine where the differences between means occurred, using the Scheffe method as suggested by Winer (1965) and Johnson \& Jones (1972). The results of these comparisons may be seen in Table 4 .

Table 4

Multiple Comparisons of Means Using the Scheffe Method on Response Suppression of Mean Number of Licks for Trials 1-5

Combined

\begin{tabular}{|c|c|c|c|c|c|c|c|c|}
\hline & PESB-50 & PESB-150 & FM-0 & $F M-50$ & FM- 150 & CS -0 & $\mathrm{CS}-50$ & CS-150 \\
\hline PESB-0 & $.2964^{*}$ & $.6795^{*}$ & .1419 & .2177 & .2024 & .0504 & .1380 & .0295 \\
\hline PESB- 50 & & $.3831^{*}$ & $.4384 *$ & .0847 & .1930 & $.4586^{*}$ & .0966 & .1584 \\
\hline PESB-150 & & & $.8215^{\%}$ & $.4678^{*}$ & $.5771^{*}$ & $.7292 *$ & $.5415^{*}$ & $.7090 *$ \\
\hline FM- 0 & & & & $.3537^{*}$ & .2444 & .0916 & .2800 & .1125 \\
\hline$F M-50$ & & & & & .1093 & .2621 & .0757 & .0737 \\
\hline$F M-150$ & & & & & & .1528 & .0356 & .0209 \\
\hline CS -0 & & & & & & & .1884 & .0209 \\
\hline CS -50 & & & & & & & & .1675 \\
\hline
\end{tabular}

Twelve comparisons produced differences large enough to exceed the critical value of .2882 (p<.05): The PESB-O group was different from the PESB-50 and PESB-150 groups, while PESB-50 differed from PESB-150, FM-0, and CS-O. The most striking differences occurred when the PESB150 group was compared to the other groups, and was significantly 
Figure 2. Mean response suppression for number of licks on Trial 1 alone. 


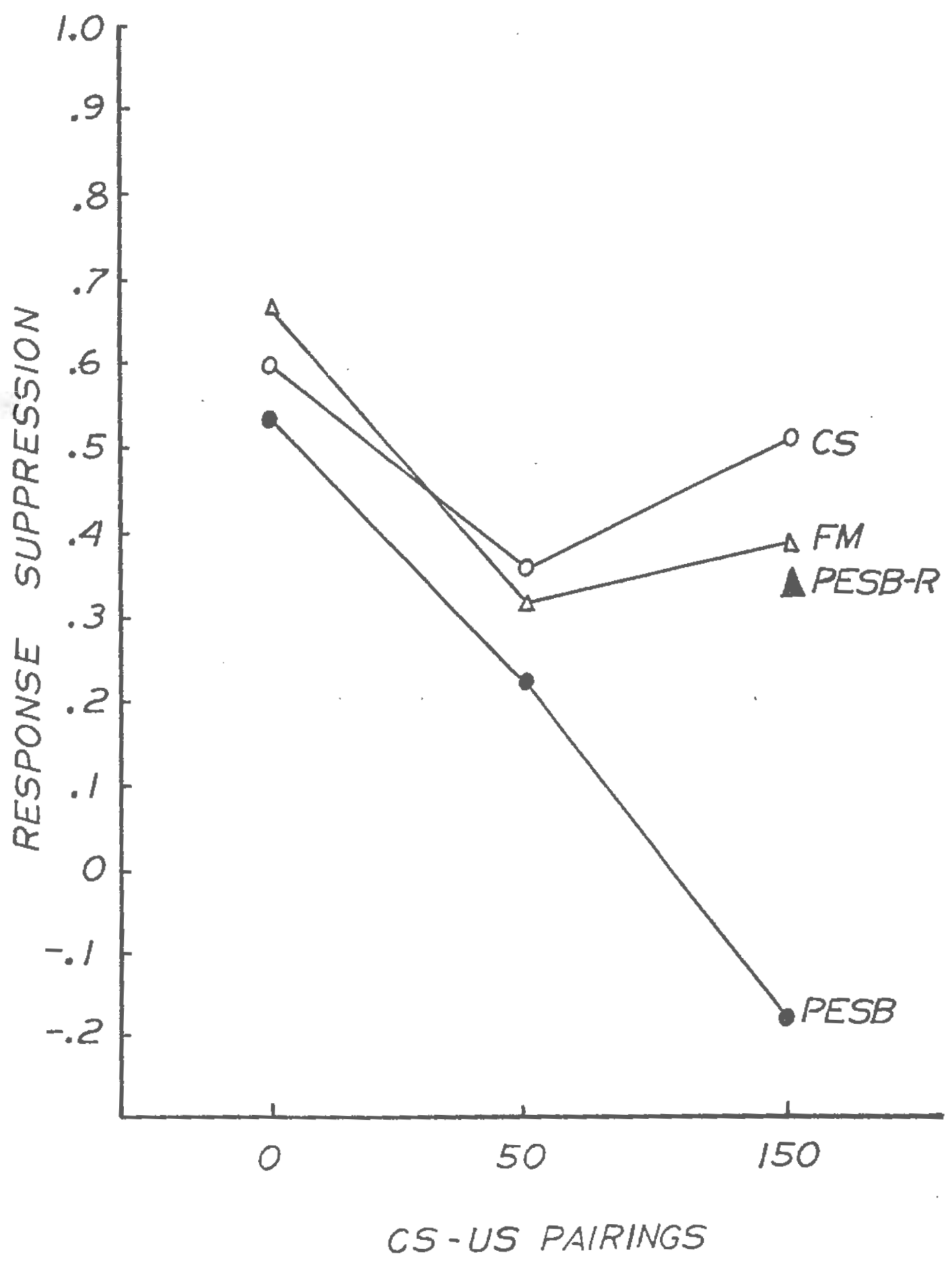


different from each of them. The only other difference large enough to reach significance occurred between the FM-0 group and the FM-50 group.

The mean response suppression of the PESB-150 Random (PESB-R) a priori control group was also compared with each of the experimental groups. Table 5 gives the results of the Dunnett's test.

Table 5

Dunnett's Test Comparing the PESB-R Control Group with all Means for Response Suppression of Number of Licks, Trials 1-5 Combined

$\begin{array}{llccccc} & \text { PESB-0 } & \text { PESB-50 } & \text { PESB-150 } & \text { FM-0 } & \text { FII-50 } & \text { FM-150 } \\ \text { PESB-R } & 7.9500^{*} & 1.6100 & 7.0828^{*} & 4.6528 * & .4000 & 1.1471 \\ & \text { CS-0 } & \text { CS-50 } & \text { CS-150 } & & & \\ \text { PESB-R } & 3.3342^{*} & .6528 & 3.0457^{*} & & & \end{array}$

${ }^{*} \mathrm{p}<.05$

The critical ratio for this Dunnett's Test was $\underline{t}(81)=2.45, \underline{p} .05$. Five significant differences occurred: PESB-R differed from PESB-0, PESB-150, FM-0, CS-0 and CS-150, however only PESB-150 showed less suppression than PESB-R.

The next set of data concerned the amount of response suppression observed on trial 1 alone, the very first time the previously feared CS was presented during the test phase. Here the results presented 
response suppression uncontaminated by any further CS exposures. As seen in Table 1 and Figure 2, the means and standard deviations reveal functions which resemble, in form, the functions seen when trials 1-5 were examined together.

Again, it appears that the most significant reduction in response suppression occurred in the PESB-150 group, but the ANOVA (see Table 6) failed to yield a significant treatment effect for type of ESB at the p.05 level. A significant effect for number of pairings occurred $\underline{F}(2.81)=19.6106, \underline{p}<.001$, along with a significant interaction, $\underline{F}(4,81)=$ $2.6115, \underline{p}<.05$.

Table 6

ANOVA Sumary Table for

Response Suppression of Number of Licks

on Trial 1

\begin{tabular}{lrrrr}
\hline Source & SS & df & MS & $\underline{F}$ \\
\hline Total & 15.1995 & 89 & .3307 & 2.9739 \\
ESB & .6615 & 2 & 2.1807 & $19.6106^{* * *}$ \\
Pairings & 4.3615 & 2 & & \\
ESB x & 1.1619 & 4 & .2904 & $2.6115^{*}$ \\
Pairings & 9.0146 & 81 & 1.111 & \\
Error & & &
\end{tabular}

${ }^{*} \mathrm{p}<.05$

$* \dot{p}<.001$ 
Subsequent tests (the Scheffé) were performed to determine which individual means differed. Table 7 below shows that there were only three differences which exceeded .5993 , the critical value needed to reach the $p<05$ level of significance.

\section{Table 7}

Multiple Comparisons of Means Using the Scheffé Method on Response Suppression of Mean Number of Licks

for Trial 1

\begin{tabular}{|c|c|c|c|c|c|c|c|}
\hline PESB- 50 & PESB-150 & $F M-O$ & $F M-50$ & FM-150 & $\mathrm{CS}-0$ & $\mathrm{CS}-50$ & CS -150 \\
\hline PESB-0 . 5970 & $.8858 *$ & .0585 & .3613 & .4987 & .2158 & .4588 & .3247 \\
\hline PESB- 50 & .3600 & .5385 & .2357 & .0983 & .3812 & .1382 & .2123 \\
\hline PESB-150 & & $.8985 *$ & .5957 & .4583 & $.7412 *$ & .4982 & .5723 \\
\hline FM-O & & & .3028 & .4402 & .1573 & .4003 & .3252 \\
\hline FM- 50 & & & & .1374 & .1455 & .0975 & .0234 \\
\hline$F M-150$ & & & & & .2829 & .0399 & .1140 \\
\hline CS -0 & & & & & & .2340 & .1689 \\
\hline $\mathrm{CS}-50$ & & & & & & & .0741 \\
\hline
\end{tabular}

*p<.05

PESB-O was significantly different from PESB-150, and PESB-150 was significantly different from FN-O and CS-O.

The results of the Dunnett's test comparing the a priori control group with all means provided in Table 8, show only two comparisons which exceeded $\underline{t}(81)=2.45, \underline{p}^{4} .05$. 
Figure 3. Mean response suppression for number of licks on trials 1 and 2 combined. 


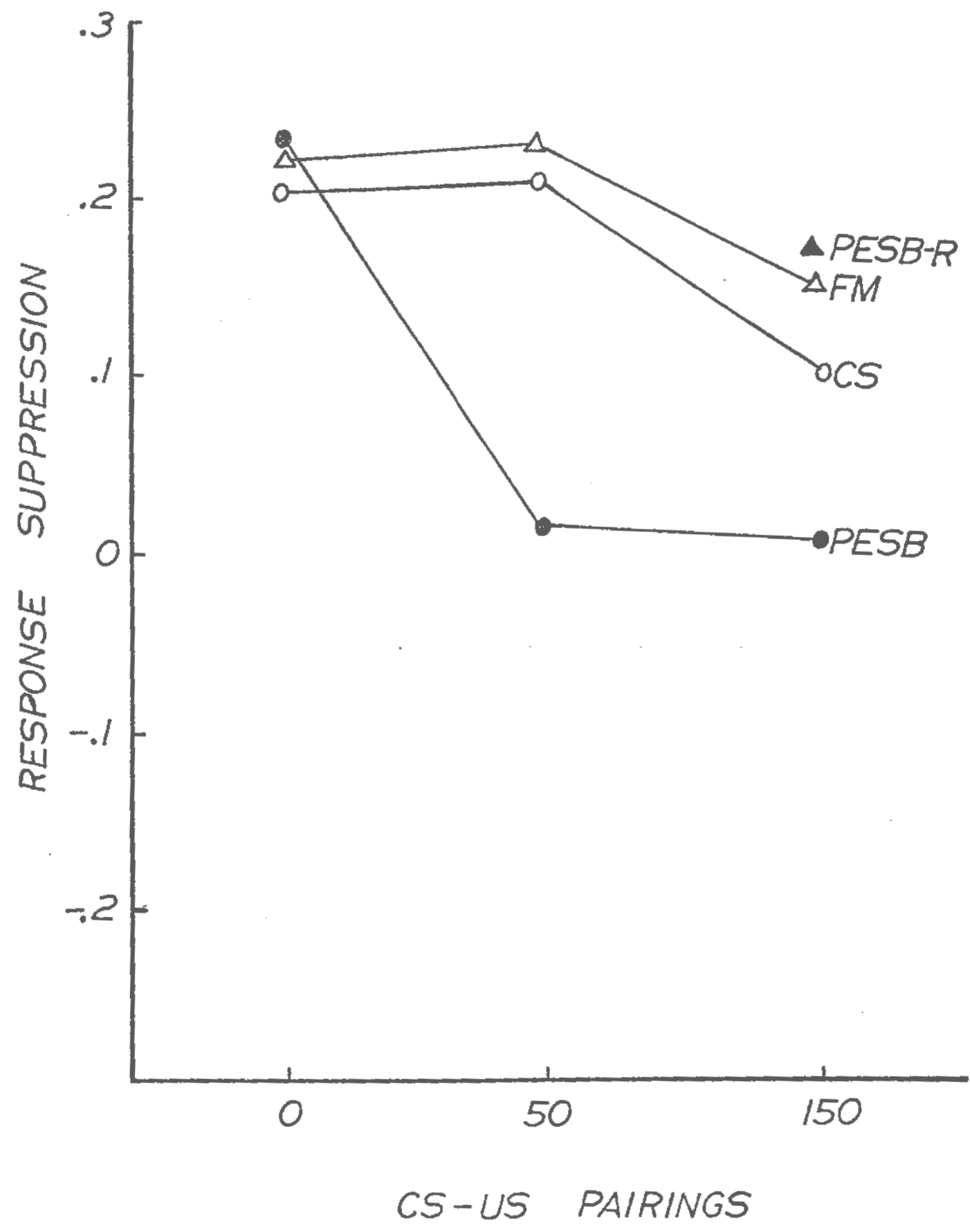


Table 8

Dunnett's Test Comparing the PESB-R Control Group with all Means for Response Suppression of Number of Licks on Trial 1

\begin{tabular}{lllllll}
\hline & PESB-0 & PESB-50 & PESB-150 & FM-0 & FM-50 & FM-150 \\
PESB-R & $2.6103^{*}$ & 1.7190 & $3.8148^{*}$ & 2.2179 & .1871 & .7619 \\
& CS-0 & CS-50 & CS-150 & & & \\
PESB-R & 1.7103 & .4558 & .0301 & & & \\
\hline${ }^{*}<-05$ & & & & & & \\
\hline
\end{tabular}

The next set of comparisons examined Trials 1 and 2 together, and provided results similar to Trials 1-5 together. Means and standard deviations can be seen in Table 1, while Figure 3 shows the functions.

The ANOVA performed on these data again showed highly significant mean defferences (see Table 9). A significant main effect occurred for $E S B$, with $\underline{F}(2,81)=4.0871, \underline{p} 4.001$; and for number of pairings, $\underline{F}(2,81)=23.2985$, $\underline{p}^{<.001}$; along with a significant interaction, $\underline{E}(4,81)=33.1444, \underline{p}<.001$. 
Table 9

ANOVA Summary Table for

Response Suppression of limber of Licks on

Trials 1 and 2

\begin{tabular}{|c|c|c|c|c|}
\hline Source & $\underline{S S}$ & df & $\underline{\mathrm{MS}}$ & $\underline{F}$ \\
\hline Total & 18.7811 & 89 & & \\
\hline ESB & .5722 & 2 & .2861 & $4.0971 *$ \\
\hline Pairings & 3.2617 & 2 & 1.6309 & $23.2985^{*}$ \\
\hline \multicolumn{5}{|l|}{$\operatorname{ESB} x$} \\
\hline Pairings & 9.2799 & 4 & 2.3199 & $33.1414^{*}$ \\
\hline Error & 5.6772 & 81 & .0700 & \\
\hline$w$ & & & & \\
\hline
\end{tabular}

Multiple comparisons performed using the Scheffe Test may be seen in Table 10 below. Only four comparisons exceeded the critical value of .4756 at $\underline{p}<.05$. 
Table 10

Multiple Comparisons of Means Using the Scheffé Method on

Response Suppression of Mean Number of Licks

for Trials 1 and 2

$\begin{array}{lcccccccc} & \text { PESB-50 } & \text { PESB-150 } & \text { FM-0 } & \text { FM-50 } & \text { FM-150 } & \text { CS-0 } & \text { CS-50 } & \text { CS-150 } \\ \text { PESB-0 } & .5159 * & .7043^{*} & .0141 & .3161 & .2563 & .0040 & .2699 & .2667 \\ \text { PESB-50 } & .3579 & .3605 & .0303 & .0901 & .3450 & .0765 & .0797 \\ \text { PESB-150 } & & .7184^{*} & .3927 & .4525 & .7092^{*} .4382 & .4421 \\ \text { FM-0 } & & & .3302 & .2704 & .0164 & .0462 & .0494 \\ \text { FM-50 } & & & & .0598 & .3147 & .0513 & .0599 \\ \text { FM-150 } & & & & & & .2549 & .0136 & .0104 \\ \text { CS-0 } & & & & & & & .2685 & .2653 \\ \text { CS-50 } & & & & & & & & \\ \end{array}$

PESB-O was significantly different from PESB-50 and PESB-150; while PESB-150 differed from FM-O and CS-O.

The comparison of the PESB $R$, control group, with all other means was again performed according to the Dunnett procedure. Table 11 shows that the only differences reaching statistical significance $(\underline{t}(81)=2.45$, p<.05) occurred between the PESB-R group and PESB-150. 
Table 11

Dunnett ${ }^{\dagger} \mathrm{s}$ Test Comparing the PESB-R Control

Group with all Means for Response Suppression of Number

Licks on Trials 1 and 2

\begin{tabular}{lllllll}
\hline & PESB-0 & PESB-50 & PESB-150 & FM-O & FM-50 & FM-150 \\
PESB-R & 2.2671 & .6644 & $3.7278^{*}$ & 2.3829 & .4081 & .0972 \\
CS-O & CS-50 & CS-150 & & \\
PESB-R & 2.2510 & .0177 & .0100 & & \\
\hline
\end{tabular}

*p $p .05$

Trials 1, 2, and 3 were also examined together. Means and standard deviations can be seen in Table 1 , and Figure 4 depicts a functional relationship similar to that shown in Figures 1,2 , and 3 .

The ANOVA performed on these data (see Table 12) resulted in significant treatment effects for ESB, $\mathrm{F}(2.81)=3.7197, \underline{p}<.001$; and for number of pairings, $F(2.81)=12.6770$, pe.001. The $F$ ratio for the interaction failed to achieve statistical significance, however. 
Table 12

ANOVA Summary Table for

Response Suppression of Number of Licks on Trials

1,2 , and 3

\begin{tabular}{|c|c|c|c|c|}
\hline Source & $\underline{S S}$ & df & $\underline{\mathrm{MS}}$ & $\underline{F}$ \\
\hline Total & 13.5295 & 89 & & \\
\hline ESB & .8363 & 2 & .4181 & $3.7197 *$ \\
\hline Pairings & 2.8499 & 2 & 1.4249 & $12.6770 *$ \\
\hline \multicolumn{5}{|l|}{ ESB $x$} \\
\hline Pairings & .7349 & 4 & .1837 & 1.6343 \\
\hline Error $_{W}$ & 9.1084 & 81 & .1124 & \\
\hline
\end{tabular}

The results of the multiple comparisons following the ANOVA can be seen in Table 13 below. Only three comparisons resulted in differences large enough to exceed the critical value of $.6027, \mathrm{p}<.05$, for this Scheffé test. PESB-O was significantly different from PESB150, while PESB-150 was different from FM-O and CS-O. 
Figure 4. Mean response suppression for number of licks on trials 1,2 , and 3 combined. 


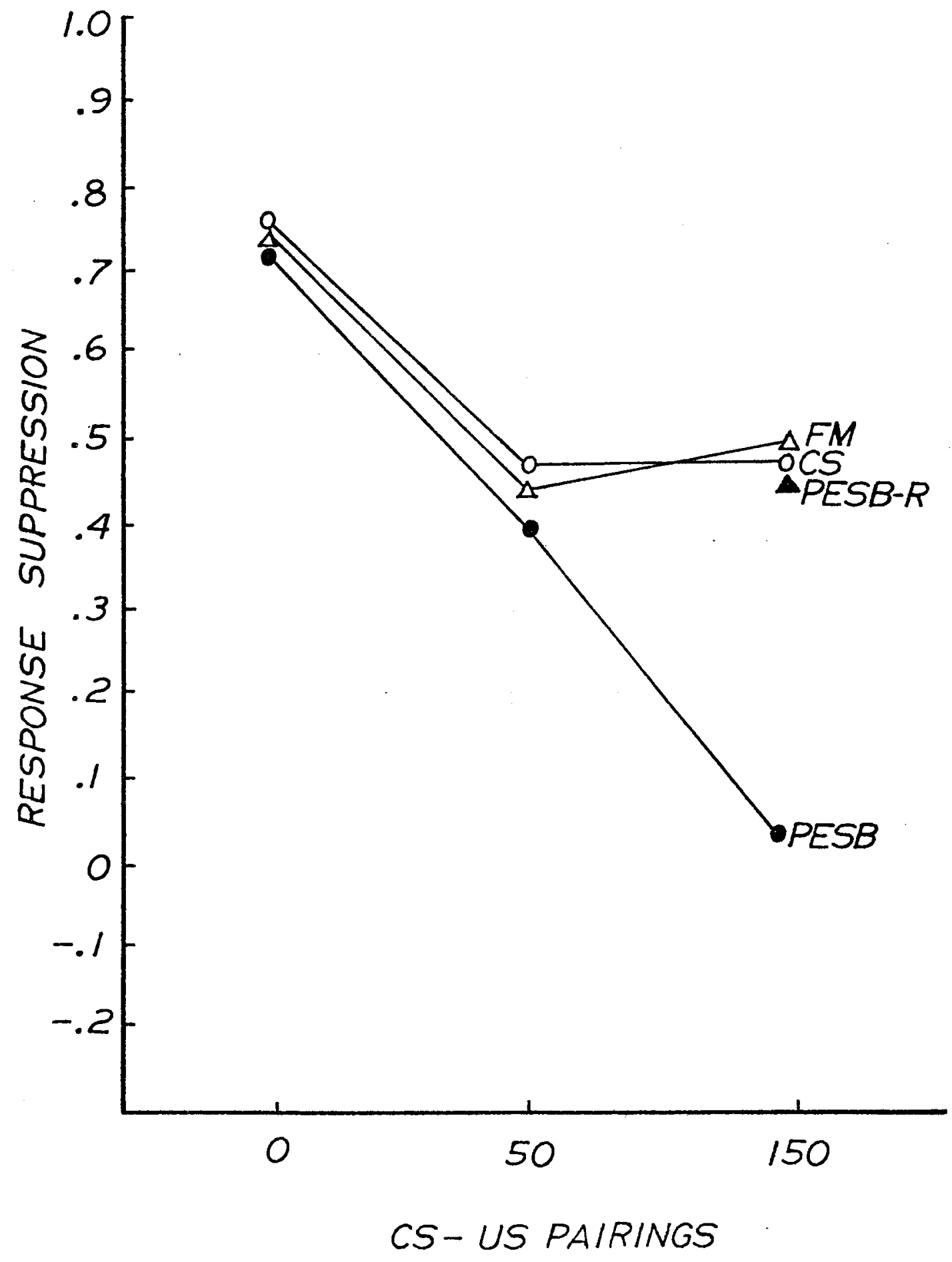


Table 13

Multiple Comparisons of Means Using the Scheffé Method on Response Suppression of Mean Number of Licks for Trials 1, 2, and 3

\begin{tabular}{|c|c|c|c|c|c|c|c|c|}
\hline & PESB-50 & PESB-150 & FM-O & FII-50 & FM- 150 & CS-O & CS -50 & CS -150 \\
\hline PESB-O & .3758 & $.6182^{*}$ & .1260 & .3162 & .1885 & .0428 & .3058 & .1194 \\
\hline PESB- 50 & & .2424 & .5018 & .0596 & .1873 & .4186 & .0700 & .2564 \\
\hline PESB-150 & & & $.7442^{*}$ & $=.3020$ & .4297 & $.6610^{\circ}$ & *. 3124 & .4988 \\
\hline$F i-0$ & & & & .4422 & .3823 & .0832 & .4318 & .2524 \\
\hline FM- 50 & & & & & .277 & .3590 & .0104 & .1968 \\
\hline FM-150 & & & & & & .2313 & .1173 & .0691 \\
\hline$c s-0$ & & & & & & & .1622 & .3486 \\
\hline CS-50 & & & & & & & & .1864 \\
\hline
\end{tabular}

Following the Scheffé test, the Dunnett's test was performed comparing the a priori control group (PESB-R) with each of the experimental groups. Table 14 below shows that only one comparison met statistical significance $(\underline{t}(81)=2.45, \underline{p}<.05)$ : PESB-R differed from FM-0. 
Table 14

Dunnett's Test Comparing the PESB-R Control Group

with all Means for Response Suppression of Number

of Licks on Trials 1, 2, and 3

\begin{tabular}{llllrll}
\hline & PESB-0 & PESB-50 & PESB-150 & FM-0 & FM-50 & FM-150 \\
PESB-R & 1.7231 & .7838 & 2.4009 & $2.5637^{*}$ & .3862 & .4656 \\
& CS-0 & CS-50 & CS-150 & & & \\
PESB-R & 2.0086 & .3168 & .9266 & & & \\
\hline${ }^{*}$ p $<.05$ & & & & & & \\
\hline
\end{tabular}

The second major dependent measure was the suppression seen in the amount of time it took each animal to make 100 licks in each of the five test periods. Table 15 provides means and standard deviations for this measure. Since no animal reached the criterion of 100 licks (in the first minute) after the second test period, only data for trials 1 and 2 will be presented. 
Figure 5. Mean Response suppression for time to 100 licks on trials 1 and 2 combined. 


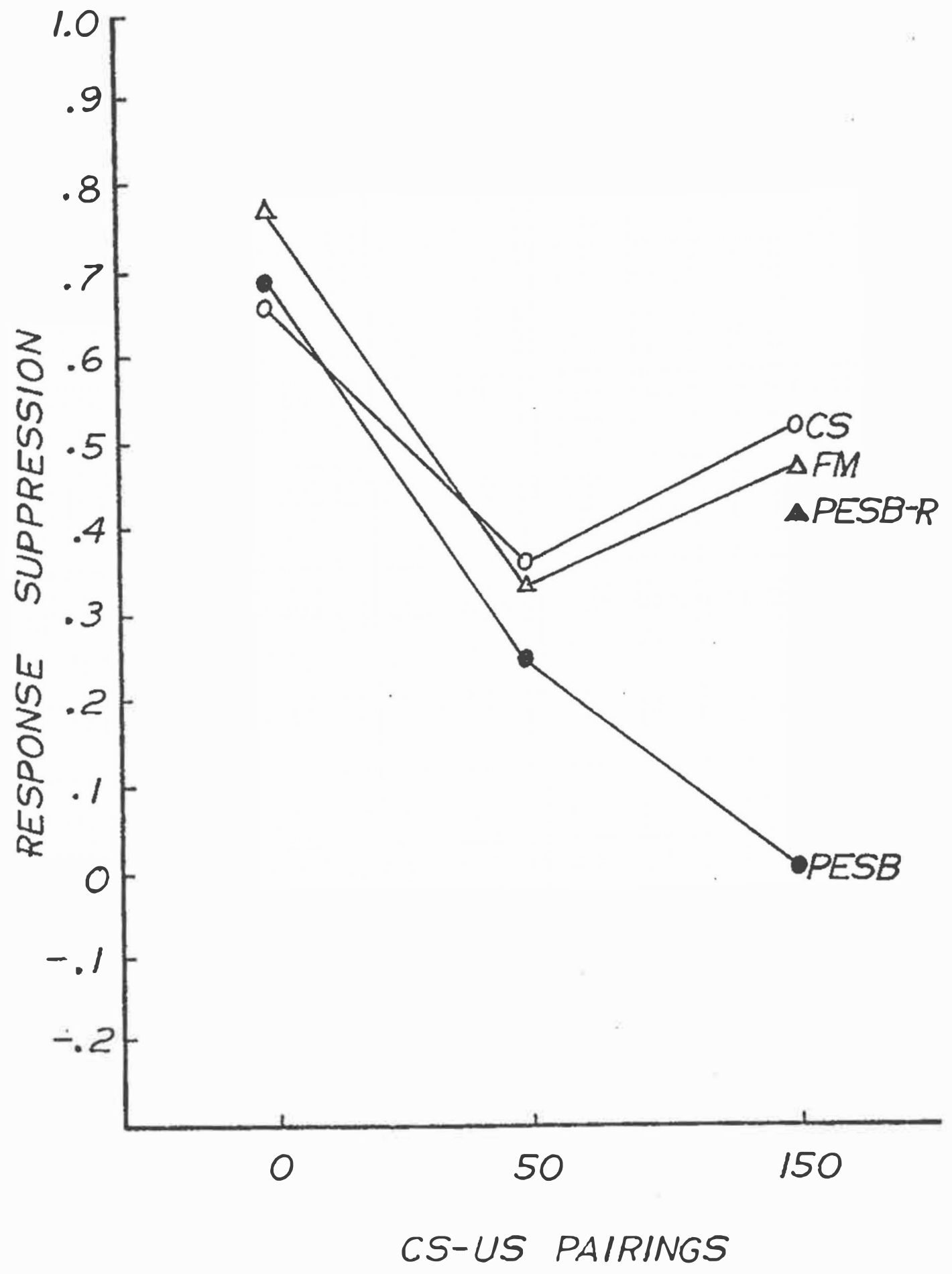


Table 15

Mean Response Suppression and Standard Deviations for Response Suppression for Each Group on Latency to 100 Licks for Trials 1 and 2

Trial 1

\begin{tabular}{lllllll} 
& PESB-0 & PESB-50. & PESB-150 & FM-O & FM-50 & FM-150 \\
\hline SD & .2819 & .1308 & -.0305 & .2967 & .2429 & .2111 \\
& .2931 & .3565 & .2415 & .2626 & .2978 & .2566 \\
& CS-0 & CS-50 & CS-150 & PESB-R & \\
SD & .2340 & .1884 & .2180 & .2864 & & \\
\hline & .2761 & .2113 & .1651 & .2208 & &
\end{tabular}

Trials 1 and 2

PESB-O $\quad$ PESB-50 PESB-150 FM-O $\quad$ FM-50 FM-150

$\begin{array}{lllllll}\mathrm{M} & .2352 & .0953 & .0441 & .2313 & .2089 & .1799 \\ \mathrm{SD} & .2132 & .1962 & .1777 & .2089 & .2445 & .1042 \\ & \text { CS-O } & \text { CS-50 } & \text { CS-150 } & \text { PESB-R } & & \end{array}$

$\begin{array}{lllll}\mathrm{M} & .2010 & .2074 & .1062 & .1607 \\ \mathrm{SD} & .1537 & .1330 & .1089 & .1291\end{array}$

Figure 5 shows the mean response suppression for this latency measure for each group. While the functions resembly those for number licks, the ANOVA resulted in only one significant main treatment effect 
(see Table 16). Number of pairings was significant, $E(2,81)=3.9704$, p<.001, but no significant ESB effect or interaction occurred when Trials 1 and 2 were examined together (F less than one).

Table 16

ANOVA Summary Table for

Mean Response Suppression on Latency to 100 Licks for

Trials 1 and 2

\begin{tabular}{|c|c|c|c|c|}
\hline Source & SS & df & $\underline{\mathrm{MS}}$ & $\underline{F}$ \\
\hline Total & 2.9374 & 89 & & \\
\hline ESB & .0598 & 2 & .0299 & .9402 \\
\hline Pairings & .2356 & 2 & .1178 & $3.9704^{*}$ \\
\hline \multicolumn{5}{|l|}{ ESB $x$} \\
\hline Pairings & .0657 & 4 & .0164 & .5157 \\
\hline${ }_{W}{ }_{W}$ & 2.5763 & 81 & .0318 & \\
\hline
\end{tabular}

Subsequent multiple comparisons of individual groups revealed no differences which exceeded the critical value set for the Scheffé test of $.3205, p^{0} .05$, as seen in Table 17 below. 
Table 17

Multiple Comparisons of Means Using the Scheffé Method on Response Suppression of Latency to 100 Licks for

Trials 1 and 2

\begin{tabular}{|c|c|c|c|c|c|c|c|c|}
\hline & PESB-50 & PESB-150 & FNI-O & $\mathrm{FM}-50$ & FMI-150 & CS-O & $\mathrm{CS}-50$ & CS -150 \\
\hline PESB-O & .1392 & .1910 & .0015 & .0556 & .0859 & .0333 & .0325 & .1369 \\
\hline PESB- 50 & & .0518 & .1343 & .0839 & .0532 & 1051 & .1067 & .0022 \\
\hline PESB-150 & & & .1895 & .1358 & 1051 & .1569 & . 1585 & .0541 \\
\hline FM-O & & & & .0514 & .0821 & .0292 & .0276 & .1331 \\
\hline$F M-50$ & & & & & .0306 & .0095 & .0227 & .0817 \\
\hline FM-150 & & & & & & .0518 & .0534 & .0510 \\
\hline CS-O & & & & & & & .0016 & .1028 \\
\hline CS -50 & & & & & & & & .1044 \\
\hline
\end{tabular}

No significant differences

The results of the Dunnett's test comparing response suppression in the PESB-R group with all means for Trials 1 and 2 together are shown in Table 18. Again no differences here exceeded the critical value of $\underline{t}(81)=2.45, \underline{p}<.05$. 
Figure 6. Mean response suppression for time to 100 licks on trial 1 alone. 


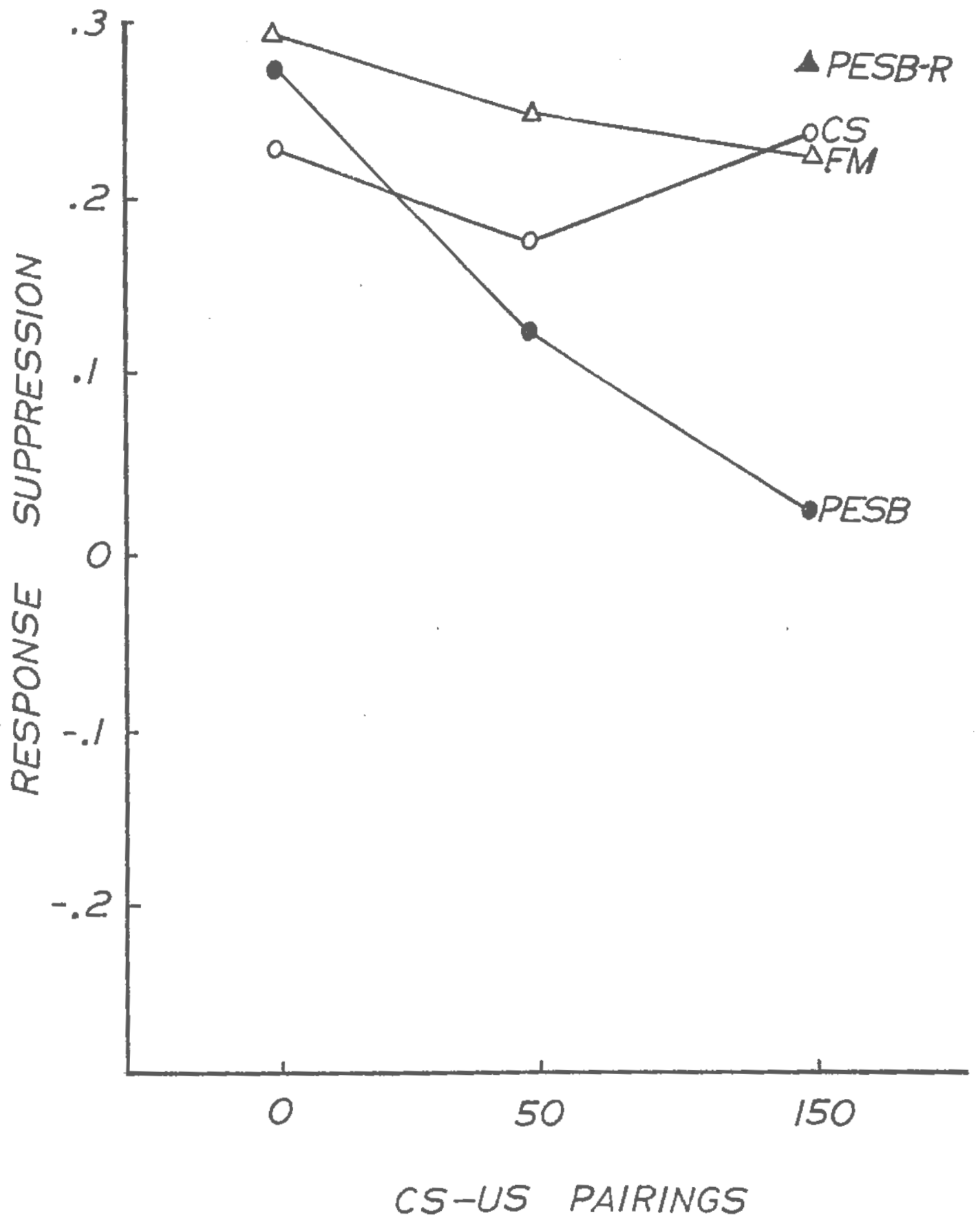


Table 18

Dumnett's Test Comparing the PESB-R Contro1

Group with all Means for Response Suppression of

Latency to 100 Licks on

Trials 1 and 2

\begin{tabular}{lcclccc} 
& PESB-0 & PESB-50 & PESB-150 & FM-0 & FM-50 & FM-150 \\
PESB-R & .9345 & .8205 & 1.4629 & .8858 & .2409 & .1530 \\
& CS-0 & CS-50 & CS-150 & & & \\
PESB-R & .5056 & .5839 & .6838 & & & \\
\hline
\end{tabular}

No significant differences

Analagous results occurred when Trial 1 was examined alone. Figure 6 depicts mean response suppression of Latency to 100 licks for each of the groups for Trial 1 alone. The results of the ANOVA performed on Trial 1 data revealed only one significant treatment effect (see Table 19). Again, only number of pairings appeared significant, $\underline{F}(2.81)=3.9111, \underline{p}<.05$, but $E S B$ and the interaction failed to reach significance. 
ANOVA Summary Table for Mean

Response Suppression of Latency to 100

Licks for Trial 1 alone

\begin{tabular}{|c|c|c|c|c|}
\hline Source & SS & $d f$ & $\underline{M S}$ & $\underline{F}$ \\
\hline Total & 2.9123 & 89 & & \\
\hline ESB & .0391 & 2 & .0195 & .6151 \\
\hline Pairings & .2150 & 2 & .1075 & $3.9111^{*}$ \\
\hline ESB $x$ & .0868 & 4 & .0217 & .6845 \\
\hline Error $_{\mathrm{W}}$ & 2.5714 & 81 & .0317 & \\
\hline
\end{tabular}

Table 20 shows the results of the Scheffé test for which three individual differences were significant and reach the critical value of .3200 for $\mathrm{p}<05$. PESB-0 was significantly different from PESB-150, while PESB-150 was significantly different from FM-O and CS-O. 
Table 20

Multiple Comparisons of Means Using the Scheffé Method on Response Suppression of Latency to 100 Licks on Trial 1

\begin{tabular}{|c|c|c|c|c|c|c|c|c|}
\hline & PESB- 50 & PESB-150 & $F M-0$ & $F M-50$ & Fil-150 & $\mathrm{CS}-\mathrm{O}$ & CS -50 & $\mathrm{CS}-150$ \\
\hline PESB-O & .1511 & $.3279 *$ & .0148 & .0390 & .0708 & .0479 & .0935 & .0639 \\
\hline $\mathrm{PESB}-50$ & & .1668 & .1669 & .1121 & .0803 & .1032 & .0576 & .0872 \\
\hline PESB-150 & & & $.3327^{*}$ & $\star 2789$ & .2471 & $.3260 *$ & .1524 & .1820 \\
\hline FM-O & & & & .0538 & .0856 & .0627 & .1083 & .0787 \\
\hline$F M-50$ & & & & & .0319 & .0089 & .0545 & .0249 \\
\hline$F M-150$ & & & & & & .0230 & .0227 & .0068 \\
\hline CS-O & & & & & & & .0456 & .0160 \\
\hline $\operatorname{CS}-50$ & & & & & & & & .0296 \\
\hline
\end{tabular}

As seen in Table 21 below, the Dunnett's procedure comparing the a priori control group, PESB-Rn with all means revealed one significant difference, PESB-R differed from PESB-150 $(\underline{t}(81)=2.45$, pr.05) 
Table 21

Dunnett's Test Comparing the PESB-R Control Group With all Means for Response Suppression of Latency to 100 Licks on Trial 1

\begin{tabular}{lllllll} 
& PESB-O & PESB-50 & PESB-150 & FM-O & FM-50 & FM-150 \\
PESB-R & .0642 & 2.2228 & $4.6057^{*}$ & .1471 & .6214 & 1.0757 \\
& CS-O & CS-50 & CS-150 & & & \\
PESB-R & .7485 & .4000 & .9971 & & & \\
\hline
\end{tabular}

*p<. 05

Twenty randomly selected subjects were then examined for histological verification of electrode placement. Examination of the slides revealed that the electrode tip had arrived directly in or very near the intended location. Figure 1 (see Appendix B) shows a photograph of a brain section containing the electrode tract for a subject with the lateral hypothalamic implant for rewarding ESB. Figure 2 (see Appendix B) shows a similar photograph for a subject with the internal capsule implant for forced movement ESB. 


\section{DISCUSSION}

The response suppression data support the major hypotheses of this study. Response prevention (RP), paired with rewarding brain stimulation, attenuated the response suppression. These results lead to the inference that fear, which was operationally defined as the suppression or interruption of ongoing behavior, had effectively been reduced through the process of classical counterconditioning.

From the analyses (both statistical and graphic) for number of licks made during the five CS-probe test periods it appears that significant fear reduction occurred only when rewarding ESB (stimulation to the lateral hypothalamus) and the CS (feared white noise) were paired together in an explicit classical delay conditioning paradigm. Analyses for latency to 100 licks, the second dependent measure, were less convincing, although similarities in terms of functions to the lick measure were obvious.

All the analyses examining test trials 1 alone through trials 1-5 together, along with the functions depicted in Figures 1-4 support a single conclusion: The only reliable significant reduction in fear resulting from the 10 treatments occurred when 150 discrete electrical stimulations to the lateral hypothalamus followed $150 \mathrm{CS}$ presentations for a total CS (RP) exposure of 75 seconds and a total stimulation (new UCS) time of 75 seconds. When the PESB-150 group was compared to all other groups, a clear relationship existed between the elinination of fear and the conditions of CS-UCS contiguity. Other differences 
occurred, however they were less consitent when trials were examined individually. When trials $1-5$ were examined together on number of licks, two other differences also occurred: CS-0 and PESB-0 differed from PESB-50 treatment. These two differences indicated a slight overall reduction of fear for the PESB-50 group, but only when examined across the five test periods. Together, these findings directly support those of Rescorla \& Solomon (1967), particularly in licht of the comparison between PESB-150 and PESB-R groups, which differed significantly when tirals $1-5$, trial 1 , and trials $1-2$ were examined together, and when examined individually. What had apparently caused the reduction in fear was specifically the forward pairing of the CS and the JSB, as both total anount of stimulation and number of pairings were the same for these groups.

This procedure defines the counterconditioning paradign, and supports the contention that counterconditioning effectively reduces fear. Particularly noteworthy is the fact that in the PESB-150 group responding was actually facilitated during the CS test probe intervals. Examination of the suppression ratios of the 10 subjects in this group revealed that in six of these subjects (during the first CS test trial) more responding (1icking) occurred during the CS than in the one minute pre-CS interval. Clearly this illustrated a change in the stimulus value of the conditioned stimuli, for in the PESB-R groups no such facilitation occurred. The previously feared CS (white noise) after pairing with rewarding brain stimulation, apparently took on facilitating qualities. The "waming" signal value of the CS which had signalled the immenence of shock (as in 
Rescorla, 1969) now signalled something else: the imnenence of rewarding brain stimulation. Increased responding in the presence of the CS after treatment implies at the very least that the CS no longer elicited what Bolles $(1970,1972)$, termed the species-specific defense reaction (SSDR) of freezing. Rather, the evidence suggests that it has become a conditioned positive stimulus.

These results support the counterconditioning explanation of fear reduction offered by Nelson (1966), Wilson \& Davison, (1971), Reid (1973) and Gordon \& Baum (1971). When a new contiguity is specified, ESB is as effective if not more so than conventional primary positive reinforcers in producing conditioned positive stimuli. An advantage of electrical stimulation of the brain may be that it can be manipulated much more precisely than conventional food or. water reinforcement. The experimenter has complete control over the onset and offset of the stimulation (01ds, 1962, 1976) and can specify the exact intensities and durations of the stimulation, along with its anatomical 1oci (01ds, 1976; Milner, 1976).

Controlling these parameters across subjects may be difficult, as each subject apparently has his own threshold for precisely the amount of stimulation that maximizes its bar pressing rate. In this study, all PESB subjects maximized their lever-pressing rates between 3.5 and 7.0 volts on our particular stimulator. Pulse duration and frequency were held constant at $6 \mathrm{~ms}$ and 100 pps respectively.

The greatest advantage of using ESB as a reinforcing stimulus stems from the fact that no motivational state need be introduced through deprivation. ESB self-stimulatory behavior is engaged in for its own sake and 
carries with it its own motivation.

From the data in this study it is apparent that the effects of ESB responded to standard conditioning parameters. Number of pairings is a variable of central importance in classical conditioning, and increasing the number of CS-UCS presentations increases the effectiveness of conditioning (Prokasy, 1972; Brogden, 1939; Hilgard \& Marquis, 1940; Rescorla \& Solomon, 1967). In this study increasing the number of CSUCS presentations increased the amount of fear attenuation. When CS exposure was held constant at 75 seconds, and number of ESB-CS pairings was changed from 50 to 150, a dramatic change in counterconditioning efficacy occurred. With 50 CS-UCS pairings no statistically greater fear reduction occurred than in no-treatment control groups except for Trials 1-5 combined. When the same CS exposure duration was broken up into 150 discrete presentations, each one preceding and signalling an ESB (UCS), a dramatic reduction in the CER was observed.

Apparently, in the PESB-50 group, 50 pairings (25 seconds of ESB) of CS and UCS was not enough to countercondition the learned fear to the white noise "CS, hence very few mean differences occurred with this group. With 150 pairings (75 seconds) of rewarding ESB, the results were unequivocal: fear was significantly attenuated with very little if any residual fear remaining (at least as measured with the CER technique in the lick situation). This may be contrasted with Monti \& Smith's (1976) data when a bar press CER was used after fifteen 20 second presentations of the CS (300 seconds of CS exposure) and much more residual fear remained after the respective $\mathrm{RP}$ treatments. 
A second variable of importance in any classical conditioning situation is the pairing method employed. The significant interaction (refer to Figures 1, 2, 3, and 4) obviously occurred because only the delay conditioning method proved effective even when 150 positive ESB's were provided. At 50 pairings, the delay method proved generally no more effective than random pairings which in turn was no more effective (statistically) than no pairings at a11. At 150 ESB-CS pairings however, unequivocal support of Rescorla's (1967) notion of the "truly randomized" control emerged. PESB-R subjects had exactly the same number and duration of CS and ESB stimulations as PESB-150 subjects, however they occurred independently of each other during the treatment session with absolutely no contiguity or contingency specified. This control is truly random, for it also lacks the contingency that presentation of the CS signals the absence of the UCS (which according to Rescorla is a contingency) informing the subject of something (possibly the safety signal of Seligman \& Johnston, 1971). The arrangement of stimuli in the PESB-R condition provided a clear way to evaluate the effect of a delay type pairing method, supporting it as probably the most significant variable determining the effectiveness of this fear reduction treatment.

It is important to note the type of delay pairing method the PESBdelay groups actually received. As it was the offset of the CS (noise) which switched on the burst of ESB in all the delay treatment groups, there was no obvious overlap in terms of both CS and ESB being on together for a portion of the total duration of the stimuli. This method might actually have been a less effective conditioning situation than a delay 
method where there is an overlap in time between the two stimuli. In any case the forward pairing was effective in reducing fear. Possibly a different delay might have caused the PESB-50 group to experience more fear reduction.

A third important variable in classical conditioning involves the intensity of the stimuli used. For the CS, the intensity was the same for all subjects, while the intensity of the UCS (ESB) by its nature had to vary a bit. The intensity (voltage of ESB) used in the counterconditioning situation was that level which provided the highest bar pressing rate in ESB screening for each individual subject. In this respect it was held constant. If the same UCS level had been employed for all subjects during the treatment, it would not have been as effective because it would not have proved equally "motivating" across subjects.

One prediction not supported by the data was that the CS alone groups (both CS-50 and CS-150) would experience significantly more fear reduction than no treatment (CS-0) control groups. The CS-50 and CS-150 groups, which both received 75 seconds of exposure to the white noise did not show more reduction in CER than the CS-0 group. Apparently 75 seconds of RP, regardless if given in fifty 1.5 second exposures or 150 , .5 second exposures was not enough total time. This finding concurs with much of the RP data; especially that of Gordon \& Baum (1971). In their study, only ESB delivered during 2.5 or 5.0 minutes with the CS on continually eliminated the active avoidance, and 5.0 minutes produced the greatest reduction.

In the present study, using the CER situation and licking as the operand, 75 seconds of total CS time was not sufficient (as seen in Baum, 1971) 
to reduce fear unless the ESB was paired with the CS in a delay conditioning paradigm. This interaction was clear in the present data: the CER was reduced significantly more than no treatment controls only in the PESB-150 group consistently through test trials 1-5.

In light of the discrepancy between these total time results and the findings of Gordon \& Baum (1971) regarding total CS time as a crucial variable, two explanations seem plausible. The first might be that the CER was actually less sensitive as a measure of fear (residual or otherwise) than Baum's (1971) active avoidance procedure. However, in light of Monti $\&$ Smith's (1976) data this seems unlikely. In addition, the performance of the CS-150 group and the PESB-R group show that indeed without ESB presentations there was a significant amount of fear remaining after the treatment. The second, more plausible explanation is that reinforcing brain stimulation was highly effective in removing the fear, to the degree that it actually produced some facilitation in responding during the test periods, while fewer pairings (50 vs 150) and less total stimulation, (25 vs 75 seconds) apparently did not have such a powerful effect. The fact that presenting $150 \mathrm{ESB}$ 's alone (PESB-0) did not reduce fear demonstrates that it was the explicit pairing of the CS with the ESB that produced the desired effect.

This second explanation seem much more tenable when one compares the PESB-150 group with the FM-150 group. When the same number of Forced Movement stimulations were administered as in the PESB-150 group, they did not attenuate the CER significantly more than the CS alone treatments (no Inore than no treatment). This comparison supports the conclusion that it 
is the affective quality of the PESB to the lateral hypothalamus that is reducing the fear as compared to any other stimulation.

Forced movement stimulation, presented in the same delay paradigm as PESB, was no more effective than no ESB. It was not apparently aversive (it did not increase the CER), it just did not seem to facilitate fear reduction. Forced movement stinulation apparently served to activate efferent motor fibers forcing the subject to move in his environment. Yet this movernent in no way reduced his fear significantly more than CS alone. These results at first seem discrepant with those of Lederhandler \& Baum (1970) who found that mechanical forced movement (literally pushing the animal around in the cage) did facilitate reduction of the active avoidance beyond that of $R P$ alone. Direct electrical stimulation of efferent motor fibers causes a qualitatively different movement in the subject when compared to pushing the animal across the floor of the cage with a mechanical paddle, forcing the subject to experience the feared environment. Electrical forced movement produces discrete involuntary movement of the head (turning to the side sharply) or body (rolling over on the side). These qualitative differences may effect the amount of fear reduction observed.

Another purpose of this study was to replicate the basic findings of Gordon \& Baum (1971) and Hunsicker et al., (1974) in a different laboratory with a different paradigm. All of the studies reported so far in the literature using ESB to facilitate fear reduction have used the active avoidance situation. Results of this study unequivocally extend these findings to a different measure: the CER. The CER probably provides a better test of fear, for it is much closer to what Bolles (1975) calls a 
species-specific defense reaction (SSDR), a first and prepotent reaction of the rat (e.g. freezing) when confronted with a new and frightening stimulus.

Clearly, when the CS was presented alone or when paired with a neutral (Forced Movement) stimulation this prepotent ability to elicit freezing (non-licking) remained. The CS, because it was paired with painful electric foot shock, continued to elicit this SSDR when presented during a test probe. On the other hand, 150 pairings of brain stimulation (PESB) and the same amount of CS eliminated the freezing, as the PESB subjects continued to lick at the tube with no significant reduction in rate during the one minute CS interval as compared to the pre-CS interval. At this time a close examination of the dependent measures is necessary. Number (or rate) of licks comprised a good operant, generating high, stable rates in all subjects right from the start of training. Any deviations from this steady rate were readily apparent in the suppression ratios calculated. Most methodological studies of licking used in a CER paradigm support the conclusion that the CER is an increasing function of the probability of CS-shock pairings (Yoshida et al., 1969; Nageishi \& Imada, 1973). Most Skinnerians today feel that the rate of response is the best measure of behavior, being particularly sensitive to states of emotionality (Reynolds, 1969; Church, 1969; Ferster et al., 1975).

Using time to 100 licks as a dependent measure for studying suppression seems much more problematic. The results in terms of response suppression of number of licks were clear and unequivocal. However, the results when latency to 100 licks in each pre- and during-CS test period 
were less clear. While the same graphic functions (Figures 5 and 6) appear as for number of licks, statistically, very little may be inferred from latency to 100 licks alone regarding the major hypotheses of this study. From the data, after the second test period the measure seemed to lose its power because of a satiation effect. Considering the fact that each subject can lick hundreds of times in one minute, satiation might occur quite rapidly. By the third test period, the subject may have received 600 or 700 drops of water. Very few subjects responded to the criterion of 100 licks after the first one minute pre and during-CS periods, and none did after the second period. The failure of these subjects to make the 100 licks in even the pre-CS periods suggests that perhaps a shorter interval or a lower criterion would have helped the latency measure a bit. Overall, the latency data from this study showed no reliable mean differences in the analyses of variance with number of ESB-CS pairings either with PESB or FM-ESB, throughout the five test periods.

A priori comparisons between the PESB-R group and all other treatment groups revealed the fact that the only significant difference occurred between PESB-R and PESB-150 on trial 1 with latency to 100 licks. Multiple cormparisons also revealed PESB-150 different from PESB-O, FM-0, and CS-0 on this measure, although the only significant $F$ ratio occurred for number of pairings, not for type of ESB.

An important implication of these results is that counterconditioning may play an important role in RP. Although this study did not use a traditiona1 RP or blocking paradigm (there was no active avoidance response) it did deal with conditioned fear, the motivator assumed to produce the 
avoidance response. A direct counterconditioning paradign did reduce apparent fear, at least that measured by the CER. This approach is directly analagous to most behavior modification counterconditioning. First, the stimuli (CS) that elicit the undesirable response (fear) are identified. Second, a response is chosen that is incompatible with the first response, and preferable to it (relaxation or pleasure in incompatible with anxiety). Third, a stimulus was found that elicits the new response (Positive ESB) and systematically the two were paired in such a way that the CS comes to elicit the "central reward" in place of the fear. This traditional explanation involves letting the original fear reaction become extinguished. It may be that respondent extinction is a subset of counterconditioning: i.e., the CR does not extinguish until another response is conditioned in its place. In counterconditioning, one specifically provides the alternative response, where pure extinction ( $R P$ alone) does not specify or control the source of the alternative response. If this hypothesis is true, counterconditioning should be potential1y more effective than simple extinction. This explanation is consistent with most of the procedures which facilitate RP (particularly those of Baum, 1969, 1970) and an increased facilitation of RP may be expected when the contingency is clearly specified in a direct counterconditioning situation. 
APPENDIX A

Design of the Study:

Basic $3 \times 3$ Analysis of Variance Design

Showing all Treatment Groups and the

A Priori Control Group 
TABLE A

Design of the Study

\begin{tabular}{|c|c|c|c|c|}
\hline & $\begin{array}{l}\text { Positive ESB } \\
\text { Delay }\end{array}$ & $\begin{array}{l}\text { Forced Movement } \\
\text { Delay }\end{array}$ & No $\mathrm{ESB}$ & $\begin{array}{l}\text { Positive } \\
\text { ESB Delay }\end{array}$ \\
\hline $\begin{array}{l}\text { O-CS } \\
\text { Pairings }\end{array}$ & $\begin{array}{l}\text { PESB-O } \\
\text { (1) }\end{array}$ & $\begin{array}{l}F+1-0^{a} \\
(4)\end{array}$ & $\begin{array}{l}C S-0^{b} \\
(7)\end{array}$ & \\
\hline $\begin{array}{l}50-\mathrm{CS} \\
\text { Pairings }\end{array}$ & $\begin{array}{l}\text { PESB-50 } \\
(2)\end{array}$ & $\begin{array}{l}\mathrm{FM}-50^{\mathrm{a}} \\
(5)\end{array}$ & $\begin{array}{l}\mathrm{CS}-50^{\mathrm{b}} \\
(8)\end{array}$ & \\
\hline $\begin{array}{l}\text { 150-CS } \\
\text { Pairings }\end{array}$ & $\begin{array}{l}\text { PESB-150 } \\
\text { (3) }\end{array}$ & $\begin{array}{l}\text { FM-150 } \\
(6)\end{array}$ & $\begin{array}{l}\operatorname{CS}-150^{b} \\
(9)\end{array}$ & $\begin{array}{l}\text { PESB-RC } \\
(10)\end{array}$ \\
\hline
\end{tabular}

Note. $\mathrm{N}$ of each cell $=10$.

asubjects matched to PESB in terms of number, duration and sequence of CS and ESB exposures

bSubjects matched to PESB in terms of number, duration and sequence of CS exposures

CSubjects matched to PESB-150 in terms of number and duration of CS and ESB's, sequence randomly determined 
APPENDIX B

Histological Results 



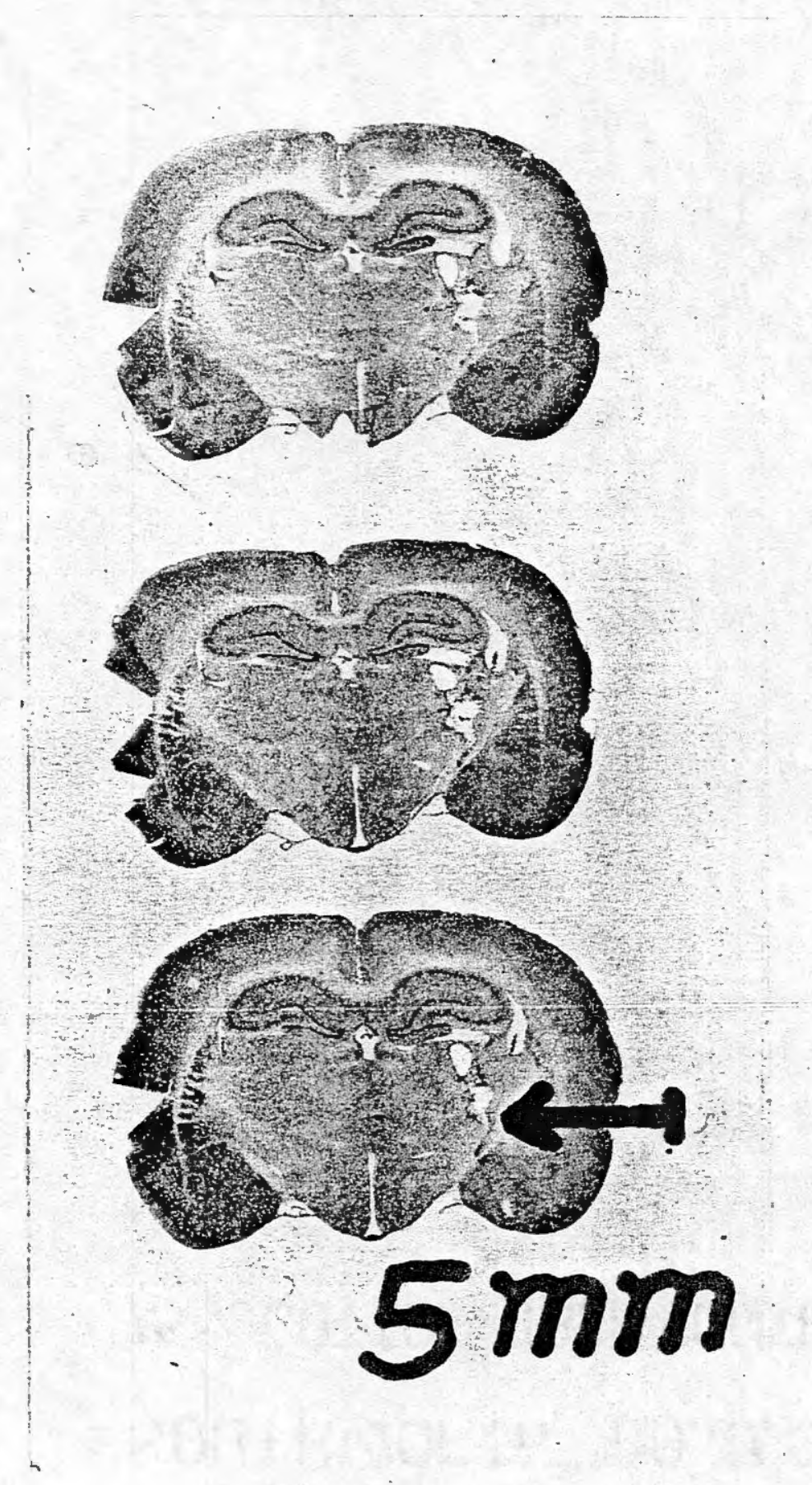

Figure 2. Brain sections from a subject with an Internal Capsule implant for forced movement ESB. 


\section{REFERENCES}

Bankart, R. E Elliot, R. Extinction of avoidance in rats: Response availability and stimulus presentation effects. Behavior Research and Therapy, 1974, 12, 53-56.

Baum, M. An automated apparatus for avoidance training of rats. Psychological Reports, 1965, 16, 1205-1211.

Baum, M. Extinction of an avoidance response following response prevention: Some parametric investigation. Canadian Journa1 of Psychology, 1969a, 23, 1-10.

Baum, M. Extinction of an avoidance response motivated by intense fear: Social facilitation of the action of response prevention (flooding) in rats. Behavior Research and Therapy, 1969b, 7., $56-62$.

Baum, M. Extinction of avoidance responding through response prevention. Psychological Bulletin, 1970, 74, 276-284.

Baum, M. \& Gordon, A. Effect of a loud buzzer applied during response prevention (flooding) in rats. Behavior Research and Therapy, $1970, \underline{8}, 287-292$.

Berman, J. S., $q$ Katzev, R. D. Factors involved in the rapid elimination of avoidance behavior. Behavior Research and Therapy, $1972,10,247-256$

Bolles, R. C. Species specific defense reactions and avoidance learning. Psychological Review, 1970, $71,32-48$.

Bolles, R. C. Reinforcement, expectancy and learning. Psychological Review. $1972, \underline{79}, 394-409$. 
Bolles, R. C. Reinforcement, expectancy, and learning. Psychological Review, $1972, \underline{79}, 394-409$.

Bolles, R. C. The comparative psychology of learning. In Gordon Bormant (d), Perspectives On Aninal Behavior. Glenview Illinois: Scott-Foresman, 1973, 280-306. Bolles, R. C. Theory of Motivation, 1975, Harper \& Row, N. Y. Brogden, W. J. Sensory preconditioning. Journal of Experimental Psychology, 1939, 25, 323-332.

Buss, R. \& Reid, L. Deconditioning persisting avoidance: Spacing counterconditioning periods during R. P. Bulletin of the Psychonomic Society, 1973, 2, 418-420.

Church, R. H. Response Suppression. In B. A. Campbell, \& R. M. Church (Eds.) Punishment, New York: Appleton, 1969.

Church, R. M. Aversive Behavior. In J. W. Kling \& L. A. Riggs (Eds.) Woodworth Eq Schlosberg's Experimental Psychology. New York: Holt, Rinehart, \& Winston, 1971.

Corriveau, D. P. \& Smith, N. F. A multivariate analysis of fear reduction and "safety test" behavior following R. P. Journal of Experimental Psychology: General. In press, 1977.

Coulter, S., Riccio. D., \& Page, H. Effects of blocking an instrumental avoidance response: Facilitated extinction by persistence of "fear". Journal of Comparative and Physiological Psychology, $1969, \underline{68}, 327-381$.

Delgado, J. M. R., New orientations in brain stimulation in A. Waquier and E. T. Rolles, (Eds.) Brain Stinulation Reward. New York: North-Holland/American Elsevier Co., 1976. 
Deutsch, J. A. \& Deutsch, D. Physiological Psychology, Homewood, III: Dorsey Press, 1966.

Estes, W. K., \& Skinner, B. D. Some quantative properties of anxiety. Journal of Experimental Psychology, 1941, 29, 390-400.

Ferster, C. B.: Cultertson, S. \& Boren, M. C. Behavior Principles, Englewood Cliffs: Prentice Hall, 1975.

Gordon, A., \& Baum, M. Increased efficacy of flooding (response prevention) in rats through positive intracranial stimulation. Journal of Comparative and Physiological Psychology, 1971, 75, $68-72$.

Hilgard, E. R., \& Marquis, D. G. Conditioning and Learning, N. Y. Appleton, 1940, 563, 565.

Hosobuchi, Y., Adams, J., \& Linchitz, R. Pain relief by electrical stimulation of the central grey matter in humans and its reversal by naloxone. Science, 1977, 197, 183-186.

Hunsicker, J., Nelson, T., \& Reid, L. Two kinds of intracranial stimulation as counterconditioners of persisting avoidance in rats. Physiological Psychology, 1973, 1, 227-230.

Johnson, R. L. \& Jones, J. Multiple comparisons and error rate. Journal of College Student Personnel, March, 1972.

Konig, J. L. R., \& Klippe1, R. A. The Rat Brain: A Stereotaxic Atlas of the Forebrain and Lower Parts of Brain Stem. Baltimore: Williams \& Wilkins, 1963. 
LeClerc, R., St-Laurent, J. \& Baum, M. Effects of rewarding aversive and neutral ICS administered during flooding (RP) in rats. Physiological Psychology, 1973, 1, 24-48.

Lederhandler, I. \& Baum, M. Mechanical facilitation of the action of response prevention (flooding) in rats. Behavior Research and Therapy, $1970, \underline{8}, 43-48$.

Levis, D. Implosive Therapy: the subhuman analogue, the strategy, and the technique. Part II. V. A. Publication, Battle Creek, Michigan, 1966.

Maatsch, J. L. Learning and fixation after a single shock trial. Journal of Comparative and Physiological Psychology, 1959, 52, 408-410.

Metja, C., Reid, L., Coon, K., Paxton, R., Prado-Alcala, R. Christy, D., Ganey, C., \& Miller, R. Methods of deconditioning avoidance: II, JSAS Catalog of Selected Documents in Psychology, $1974,4,119$.

Milner, P. M. Models of motivation and reinforcement. In Waquier and Rolls (Eds.) Brain Stimulation Reward, New York: North Holland Elsevier Co., 1976, 543-556.

Monti, P. \& Smith, N. Residual fear of the conditioned stimulus as a function of response prevention after avoidance or classical defensive conditioning in the rat. Journal of Experimental Psychology: General, 1876, 105, No. 2, 148-162.

Mowrer, O. H. Learning Theory and Behavior. New York: Wiley, 1960. 
Nageishi, Y. \& Imada, H. Suppression of licking behavior in rats as a function of predictability of shock and probability of CS-shock pairings. Journal of Comparative and Physiological Psychology, 1964, 87, 1105-1173.

Nelson, F. Effects of two counterconditioning procedures on the extinction of fear. Journal of Comparative and Physiological Psychology, 1966, 62, 208-213.

Olds, J., \& Milner, P. M. Positive reinforcement produced by electrical stimulation of the septal area and the other regions of the brain. Journal of Comparative and Physiological Psychology, 1964, 47, 419-427.

Olds, J. HypothaIamic substrates of reward. Physiological Review, $1962, \underline{42}, 554-604$.

olds, J. The central nervous system and the reinforcement of behavior. American Psychologist, 1969, 24, 114-132.

olds, J.; Allan, W. S.; Briese, E. Differentiation of hypothalamic drive and reward centers. American Journal of Physiology, $1971,221,368-375$.

Olds, J. Reward and drive neurons: 1976. In Waquier \& Rolls (Eds.) Brain Stimulation Reward, New York: North Holland Elsevier Co., 1976, 1-30.

Page, H. A. The facilitation of experinental extinction by response prevention as a function of the acquisition of a new response. Journal of Comparative and Physiological Psychology, 1955, $\underline{48}, 14-16$. 
Page, H. A. \& Hall, J. Experimental extinction as a function of the prevention of a response. Journal of Comparative and Physiological Psychology, 1953, 46, 33-34.

Paxton, R. A., Metja, C. L., \& Reid, L. D. Counterconditioning with and without response prevention in deconditioning persisting avoidance. Physiological Psychology, 1975.

Prado-Alcala, R., Bush, H., Steele, D., and Reid, L., Brief flooding and counterconditioning as treatments for persisting avoidance. Physiological Psychology, 1973, 1, 389-393.

Prokasy, W. F. in Black, A. H. and Prokasy, W. G. Classical Conditioning II; Current Research and Theory, N. Y. Appleton, 1972.

Reid, L. Processes of fear reduction in systematic desensitization: An addendum to Wilson \& Davison. Psychological Bulletin, 1973, 79, $107-109$.

Rescorla, B. A. Pavlovian conditioning and its proper control procedures. Psychological Review, 1967, 74, 71-80.

Rescorla, B. \& Solomon, R. Two-process learning theory: Relationships between Pavlovian conditioning and instrumental learning. Psychological Review, 1967, 74, 151-180.

Reynolds, G. S. A Primer of Operant Conditioning, Glenview Ill: Scott, Foresman \& Co., 1968

Riccio, D. C. and Silvestri, R. Extinction of avoidance behavior and the problem of residual fear. Behavior Research and Therapy, 1973, 11, 1-9. 
Rorbaugh, M., Riccio, D., \& Arthur, A. Paradoxical enhancement of conditioned suppression. Behavior Research and Therapy, $1972, \underline{10}, 125-130$.

Schiff, R., Smith, M., \& Prochaska, J. Facilitation of extinction of an avoidance response by response blocking. Journal of Comparative and Physiological Psychology, 1972, 81, 356-359.

Seligman, M. E. P., \& Johnston, J. C. A cognitive theory of avoidance learning. In.F. J. McGuigan \& D. Barry Lumsdem, Contemporary Approaches to Conditioning and Learning. Washington: V. H. Winston \& Sons, 1973, 69-110.

Shipley, R. H., Mock, L. A., Levis, D. J. Effects of several response prevention procedures on activity, avoidance responding and conditioned fear in rats. Journal of Comparative and Physiological Psychology, 1971a, 77, 256-270.

Solomon, R. L., Kamin, L. J., \& Wynne, L. C. Traumatic avoidance procedures with dogs. Journal of Abnormal and Social Psychology, 1953, 48, 291-302.

Solomon, R. L. \& Wynne, L. C. Traumatic avoidance learning: Acquisition in normal dogs. Psychological Monographs, 1953, 67, (Whole no. 354).

Spring, D., Prochaska, J., \& Smith, N. Fear reduction in rats through avoidance blocking. Behavior Research and Therapy, $1974, \underline{12}, 29-34$.

Stampfl, T. Implosive therapy: The theory, $\underline{\text {. }}$ A. Publication, Battle Creek, Michigan, 1966. 
Stampf1, T. and Levis, D. The essentials of implosive therapy:

A learning theory based psychodynamic behavioral therapy. Journal of Abnormal Psychology, 1967, 72, 596-503.

Stampf1, T., \& Levis, D. J. Implosive therapy: a behavioral therapy. Behavior Research and Therapy, 1968, 6, 31=36.

Testa, T. J. Comments on: Residual fear of the conditioned stimulus as a function of response prevention after avoidance or classical defensive conditioning in the rat. Journal of Experimental Psychology, 1976, 105, 163-168.

Thompson, R. F. Introduction to Physiological Psychology, New York: Harper \& Row, 1965. Valenstein, E. C. The anatomical Iocus of reinforcement. In E. Stellar \& J. M. Sprague (Eds.) Progress in Physiological Psychology, Vol. 1, New lork: Academic Press, 1966. Valenstein, E. S. The interpretation of behavior evoked by brain stimulation. In Waquier and Rolles(Eds.) Brain Stimulation Reward, North Holland, New York: Elsevier Co., 1976, 557-566. Voss, E., Metja, C., \& Reid, L. Wethods of deconditioning persisting avoidance: Response prevention and counterconditioning after extensive training. Bulletin of the Psychonomic Society, $1974,3,345-347$.

Waquier, A., \& Rolles, E. T. (Eds.) Brain Stimulation Reward, New York: North Holland Elsevier Publishing Co., 1976.

Winer, B. J. Statistical Principles in Experimental Design, New York: McGraw-Hil1, 1965. 
Wilson, E. T., \& Davison, G. C., Processes of fear reduction in systematic desensitization: Animal studies. Psychological Bulletin, 1971, 76, 1-14.

Yoshida, T., Masako, K., \& Hiroshi. A methodological study of the CER in rats with licking as the criterion response. Japanese Psychological Research, 1969, 2, 66-75. 